\title{
Sustainable energy systems: addressing the myriad uncertainties
}

\author{
Professor Joe Clarke \\ Energy Systems Research Unit \\ University of Strathclyde \\ joe@esru.strath.ac.uk
}




\section{Institut d'Etudes Scientifiques de Cargèse}

SIMUREX 2012 : Impact de la fiabilité des modèles et des incertitudes

\section{Sustainable energy systems: addressing the myriad uncertainties}

\section{Professor Joe Clarke} Energy Systems Research Unit

University of Strathclyde joe@esru.strath.ac.uk 


\section{Sustainable energy systems}
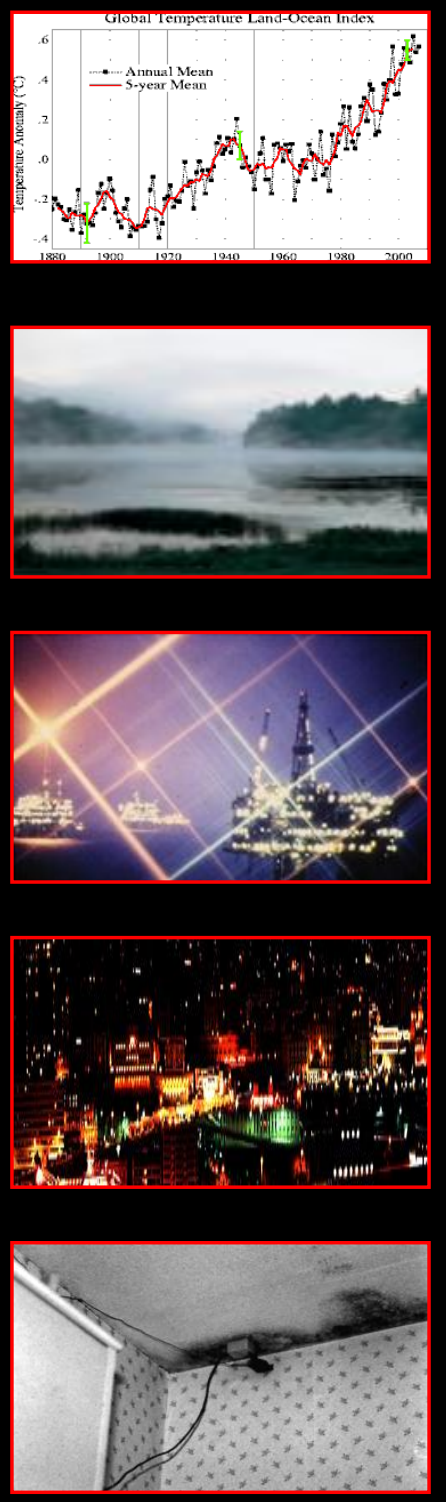

Different perspectives:

$\square$ human well-being (moral obligation)

$\square$ climate change mitigation (save the planet)

$\square$ environment protection (healthy habitats)

$\square$ fossil fuel replacement (economic growth)

$\square$ security of supply (political autonomy)

Reduce/reshape energy demand:

$\square$ population control (not an option)

$\square$ lifestyle change (do a little, save a little)

$\square$ apt technologies (plethora of options)
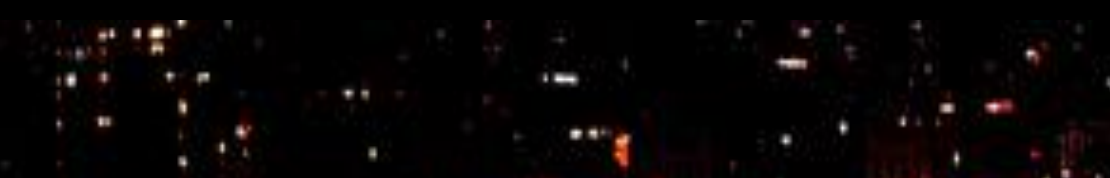

Deploy clean energy sources:

$\square$ clean fossil fuels

$\square$ nuclear fission (fusion)

$\square$ new \& renewable energy

accommodate
disparate views
while taking
effective action.

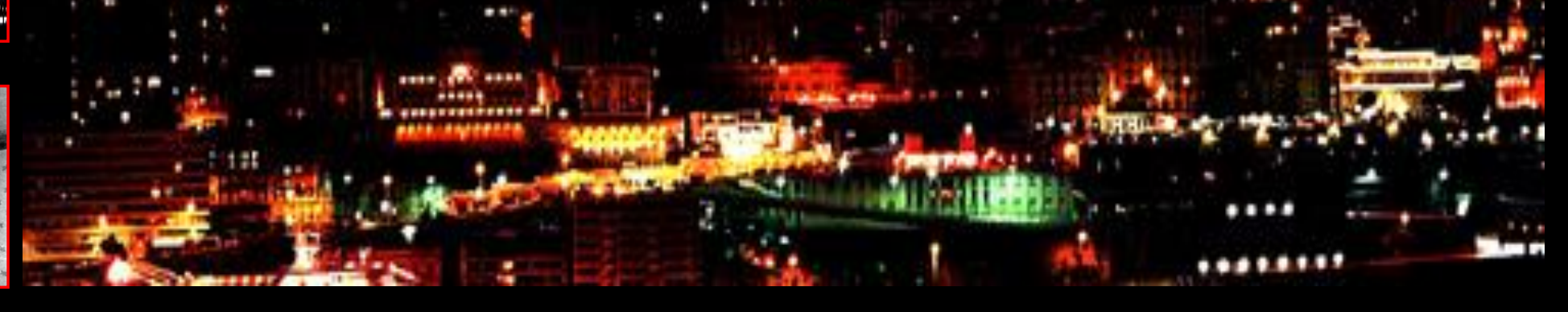




\section{Conflicting viewpoints}
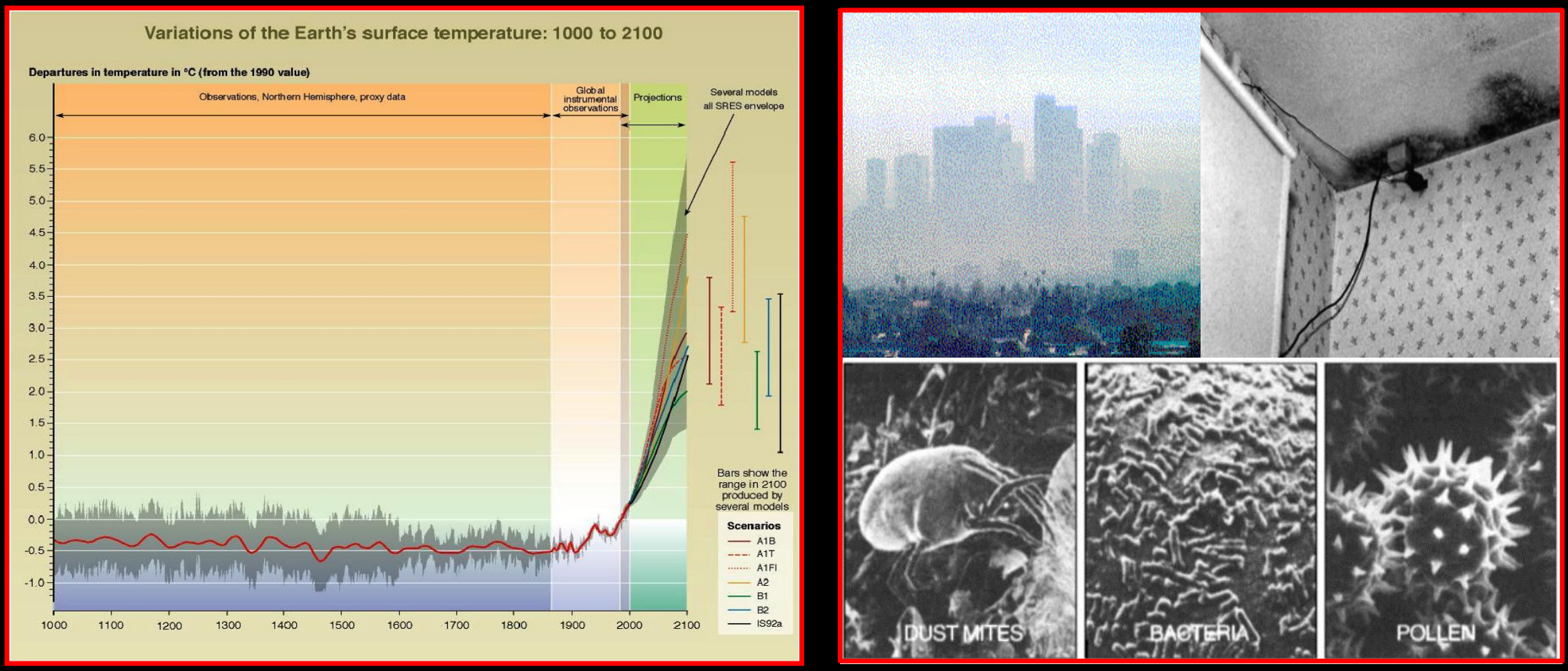

Caution!:

$\square$ energy efficiency measures may exacerbate indoor air quality;

$\square$ decentralised power production reduces global emissions but moves them to the breathing zone;

$\square$ increased system complexity may increase capital, operating and maintenance costs. 


\section{Lifestyle change}

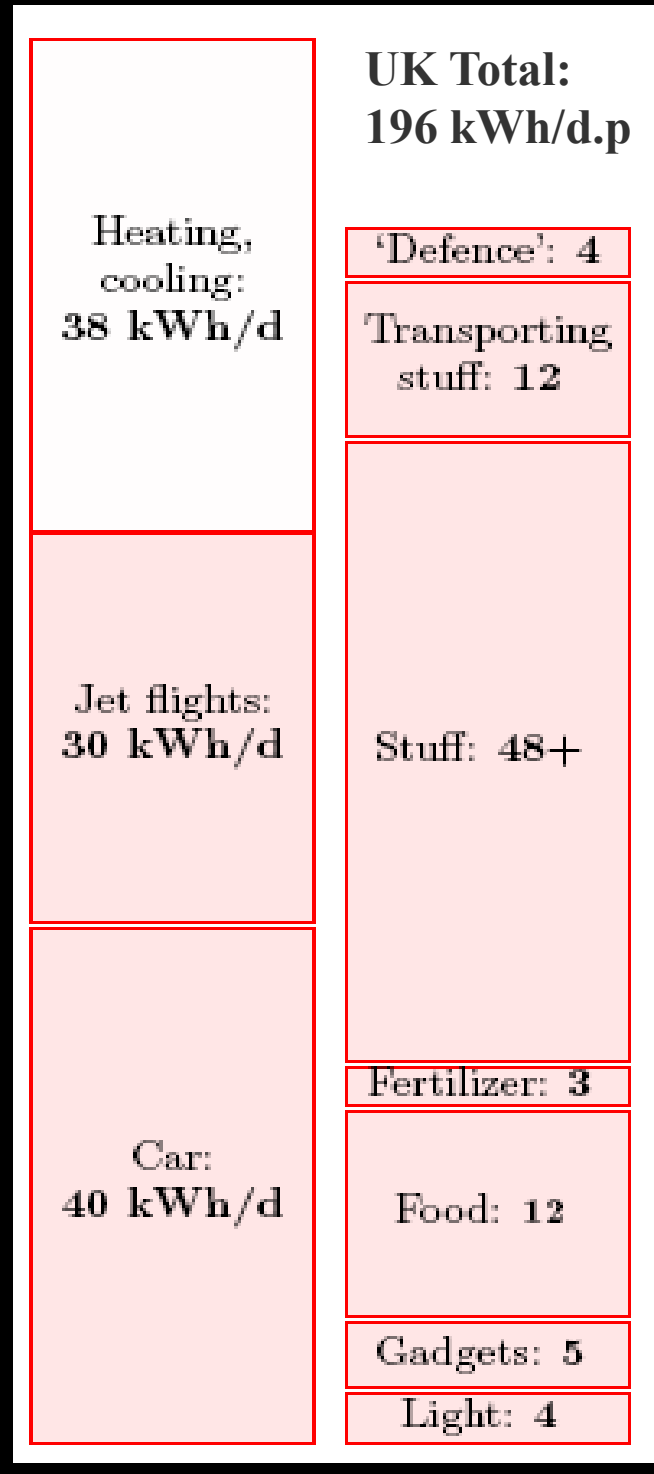

Source: MacKay, www.withouthotair.com
'Simple' actions

Possible saving (kWh/d.p)

Frugal heating system use

20

Switch off appliances at home/work $\quad 4$

Stop flying $\quad 35$

Efficient transport 20

Do not replace gadgets

Use CFL or LED

Avoid clutter

Become vegetarian

Sub-total

Lifestyle change is 4

unlikely to result in 20

substantial energy

demand reduction.

4

5

4

10

117

\section{'Difficult' actions}

Eliminate draughts

Double glazing

Improve insulation

Solar hot water panels

Photovoltaic panels

Replace old building with new

Electric heat pump for heating

Sub-total

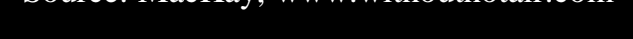




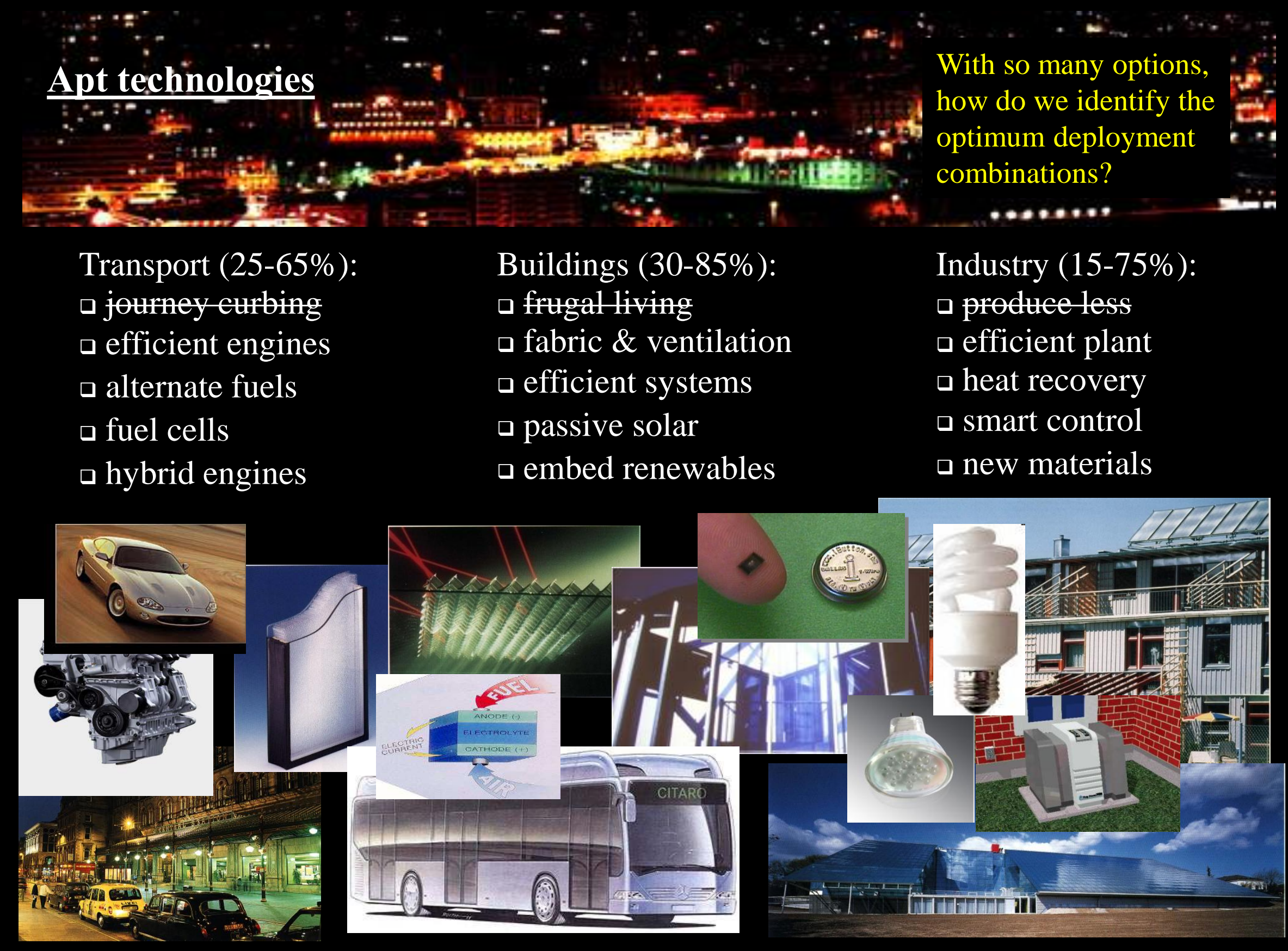




\section{Fossil fuels}

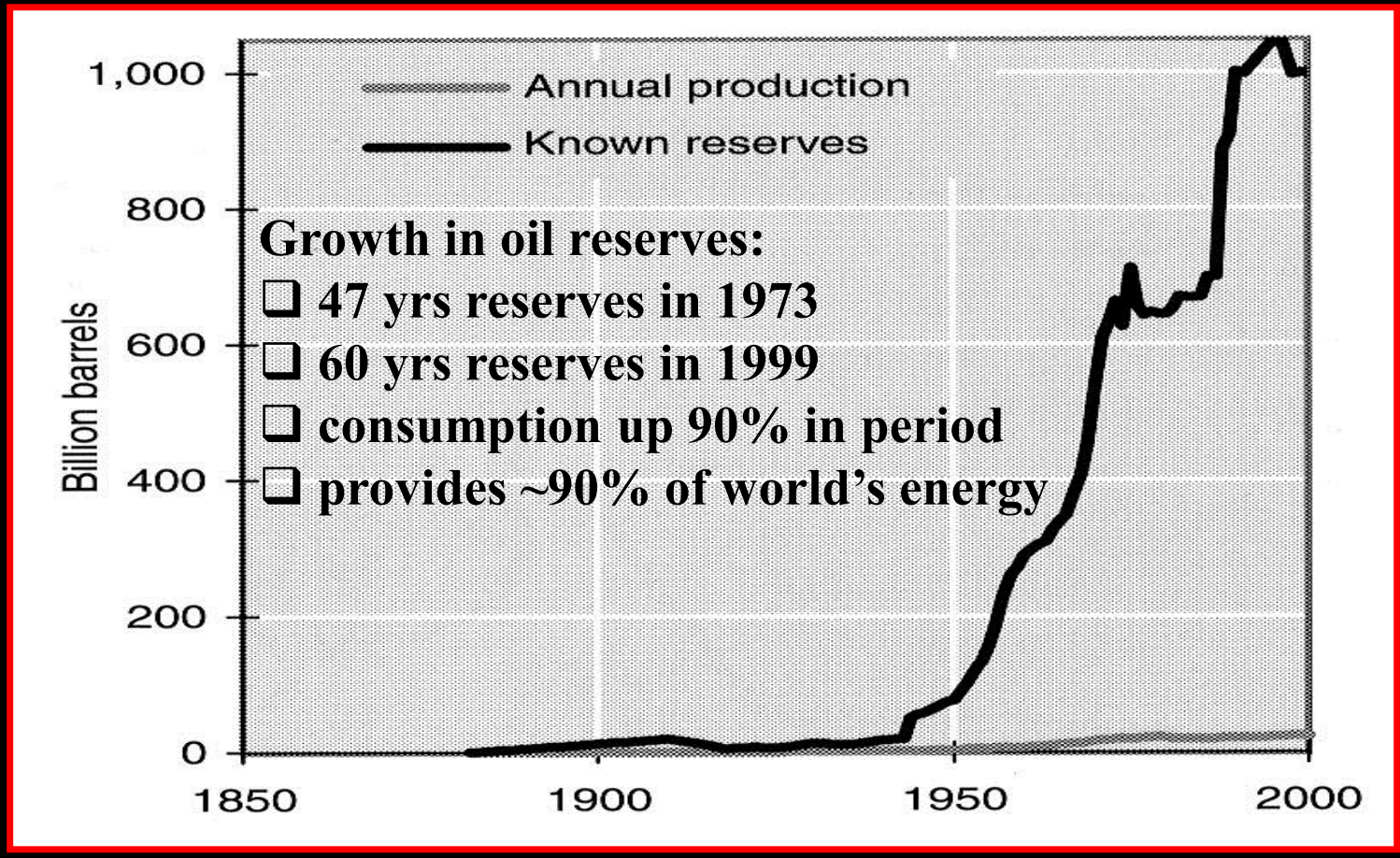

Reserves:

C Coal 230-1500 yrs;

$\square$ Oil 40-250 yrs;

$\square$ Gas 60 yrs.

Outlook:

global energy spend $<2 \%$ of GDP;

ㄴ UK spend $6 \%$ of GDP (£75b/y; c.f. £10b/y spent on discarded food);

$\square$ will dominate the world economy for 30 years or more.

Challenges:

$\square$ refine exploration techniques;

$\square$ make less 'polluting' (e.g. decarbonise);

$\square$ enhanced extraction (e.g. sequestrate C);

$\square$ new resources (e.g. coal bed methane, oil shale, tar sand)

$\square$ new uses (e.g. methanol production) 


\section{Nuclear}

"We made the mistake of lumping energy in with nuclear weapons, as if all things nuclear were evil. I think that's a big mistake, as if you lumped nuclear medicine in with nuclear weapons."

Patrick Moore, Greenpeace Co-founder

Fission:

$\square \sim 6 \%$ of global energy production;

$\square$ more expensive than fossil-based power generation but less expensive than most renewables;

$\square$ radioactive waste is a problem (transmutation initiatives);

100 years of $U_{235 ;}$

$\square 14,000$ years of $\mathrm{U}_{238}$ but security problematic.

Fusion:

$\square$ abundant fuel supply (sea water);

$\square 1 \mathrm{~g}$ equivalent to 45 barrels of oil;

$\square$ little radioactive waste;

$\square$ astronomical temperatures required;

$\square$ commercial by 22 nd century?

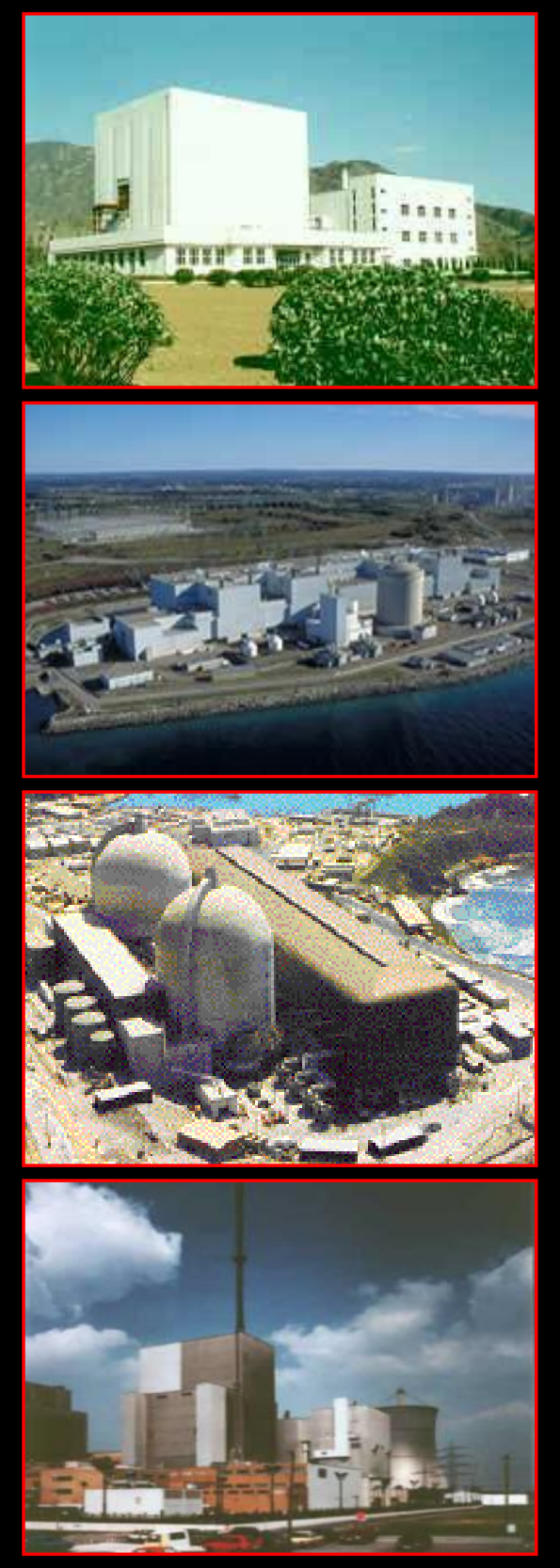




\section{Strategic renewable energy}

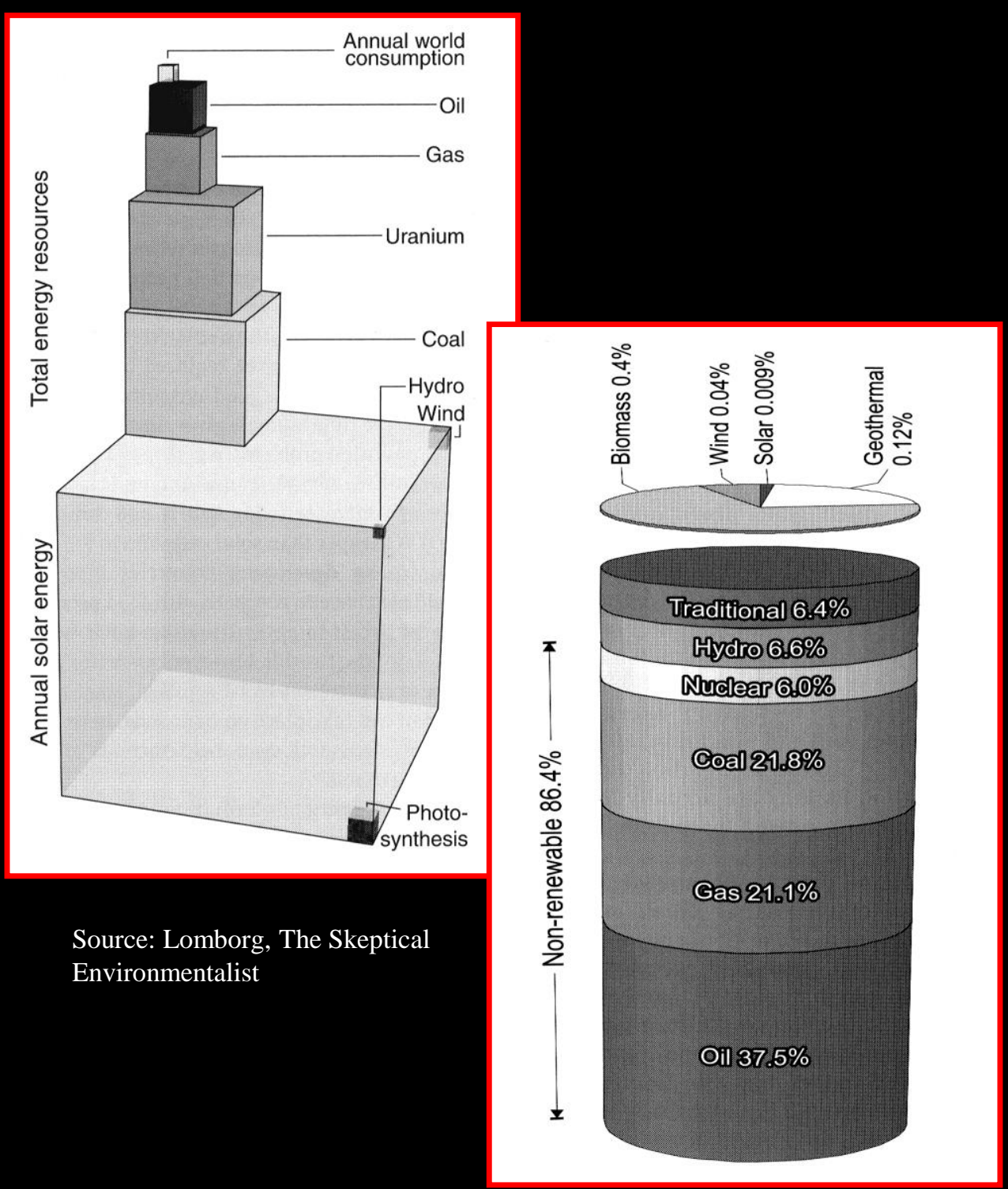

To avoid problems with fault clearance, network balancing and power quality, distributed RE systems with limited control possibility should be restricted to $\sim 25 \%$ of network capacity.

High capture levels require:

- increased transmission network capacity;

- active distribution network management;

- energy storage and/or standby capacity.

$\square$ Practical resource not vast relative to total demand.

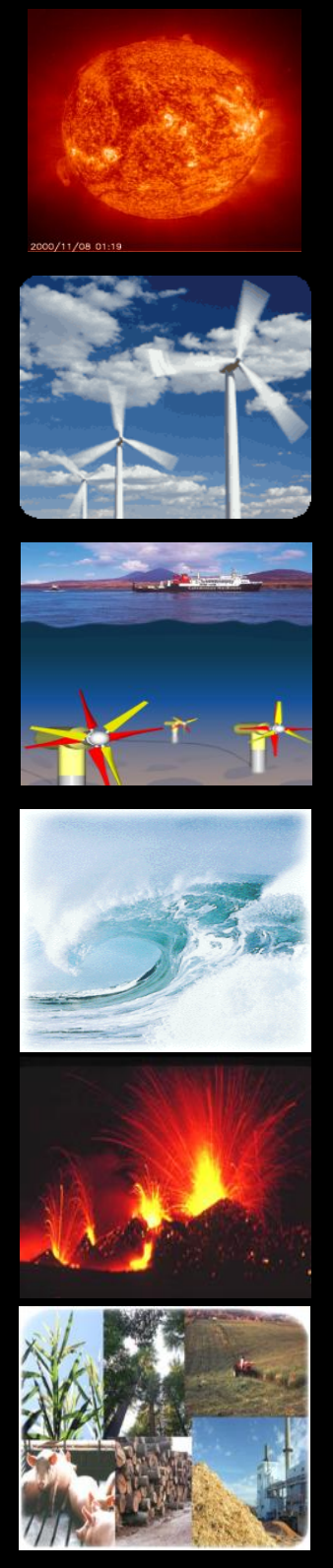




\section{Strategic renewable energy}

UK energy consumption $(196 \mathrm{kWh} / \mathrm{d} . \mathrm{p})$

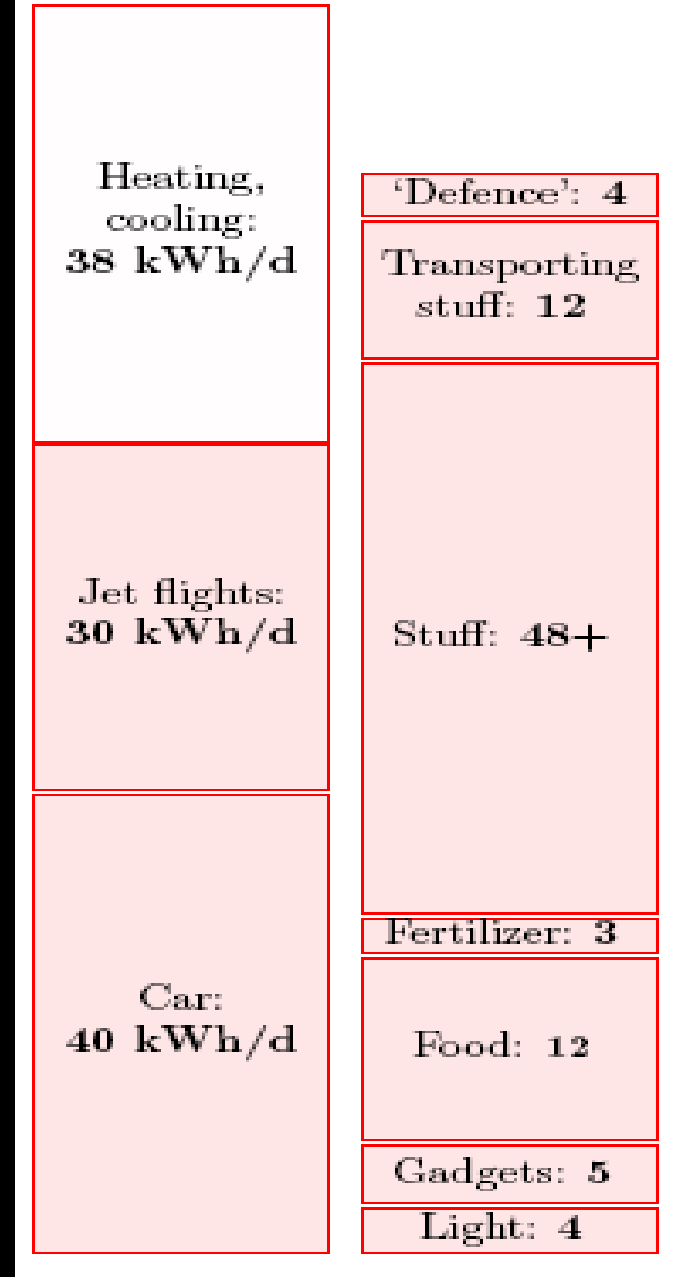

Maximum conceivable UK sustainable production $(174 \mathrm{kWh} / \mathrm{d} . \mathrm{p})$

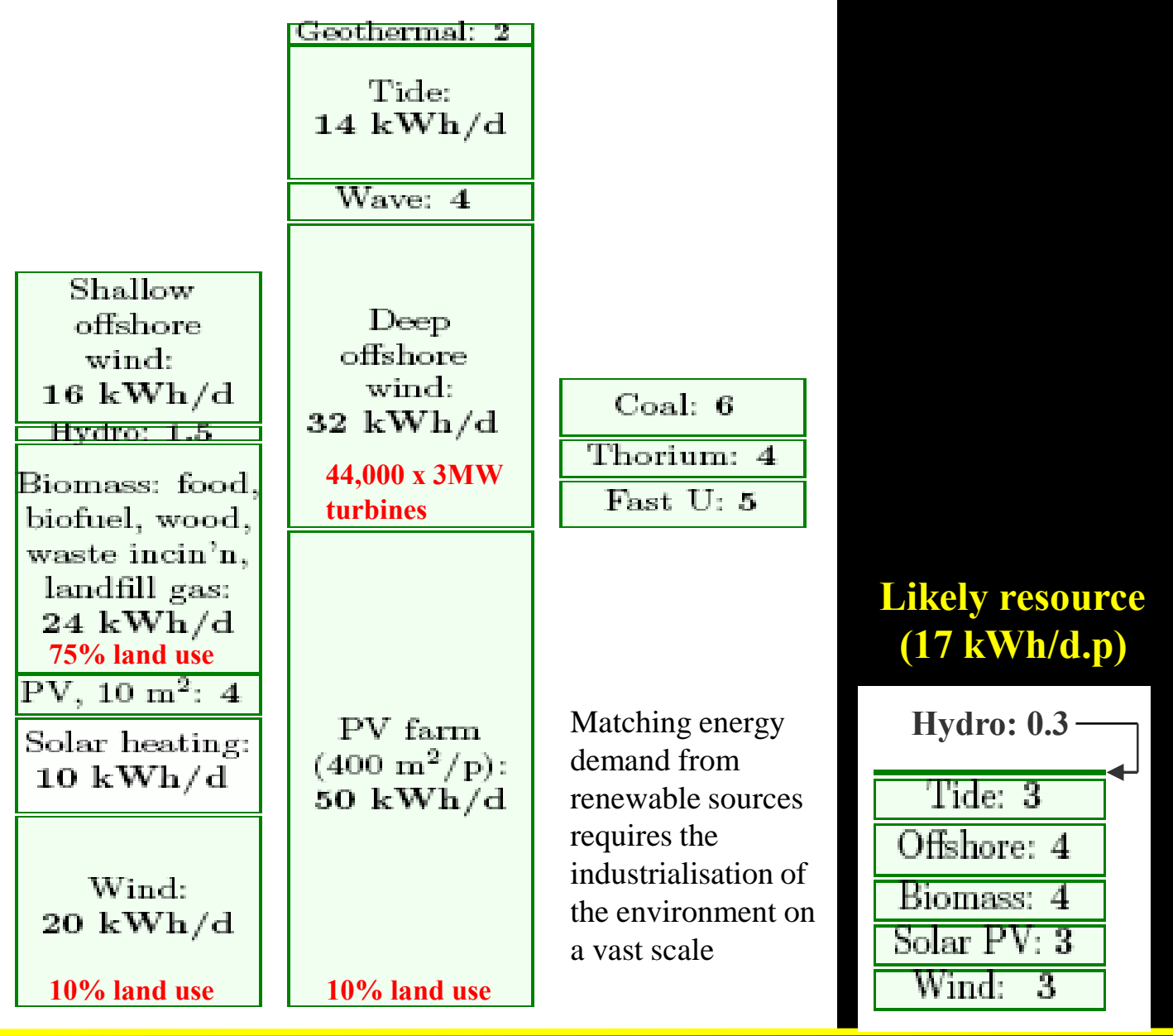

Source: MacKay, www.withouthotair.com 


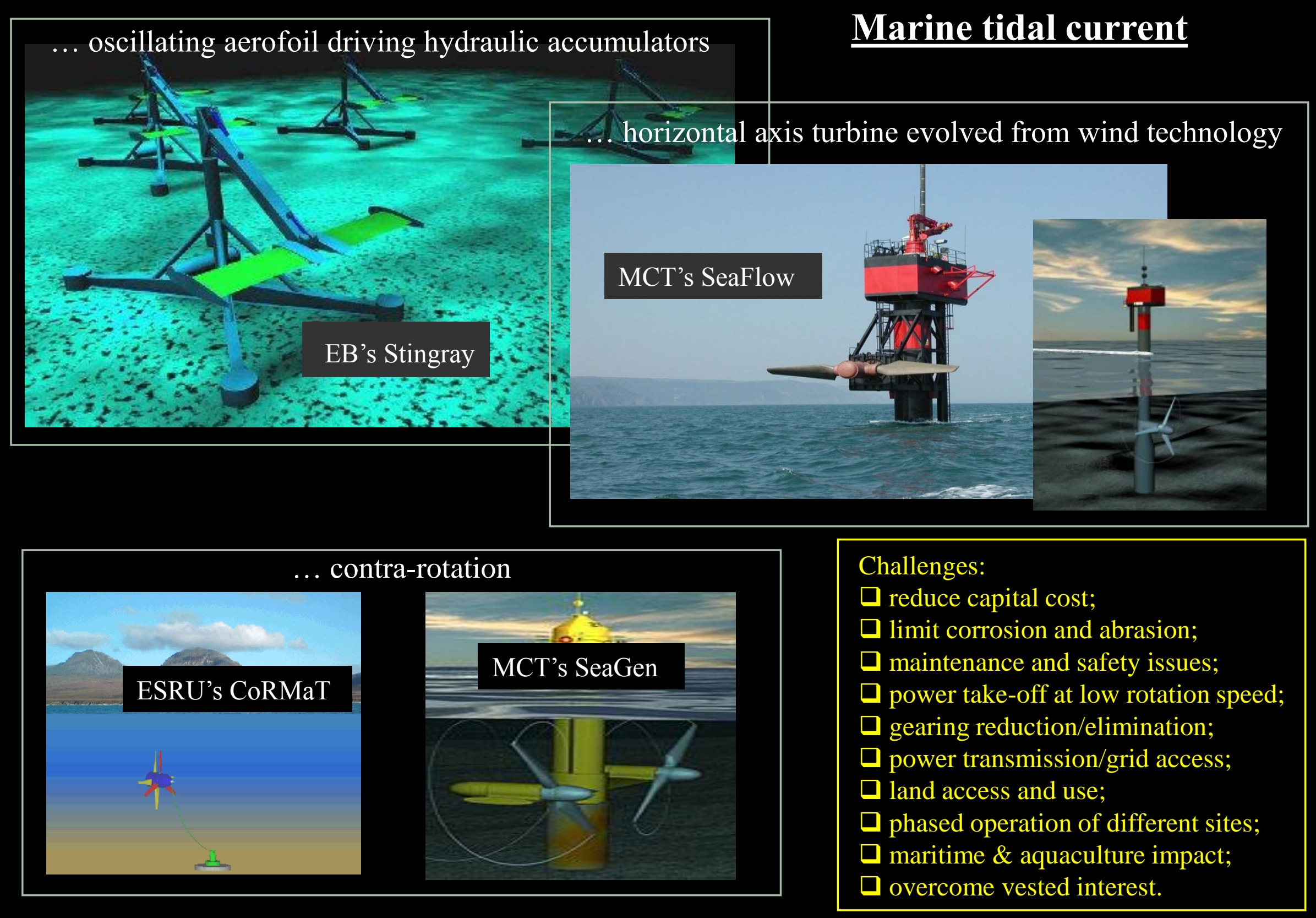




\section{Energy supply scenarios}
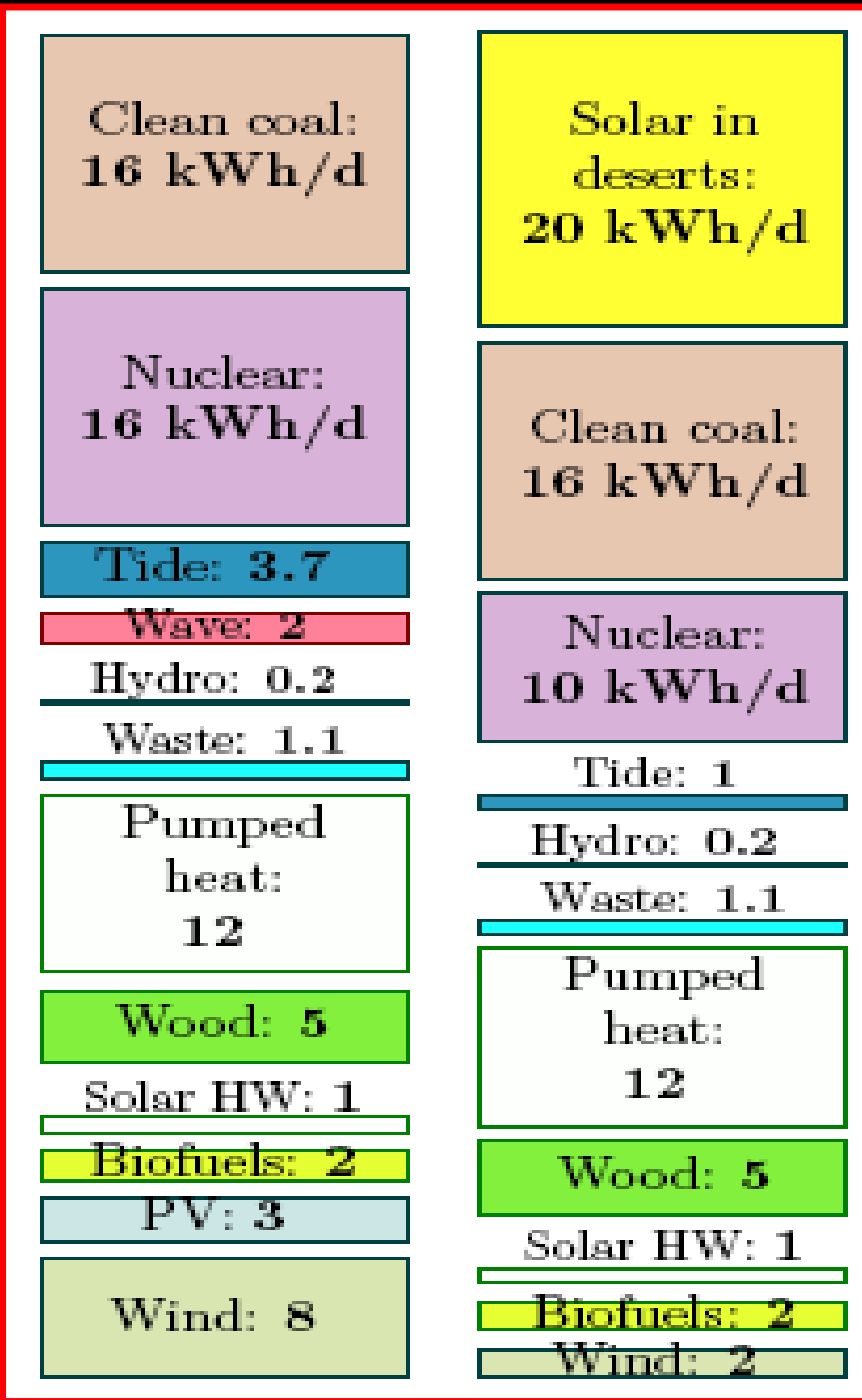

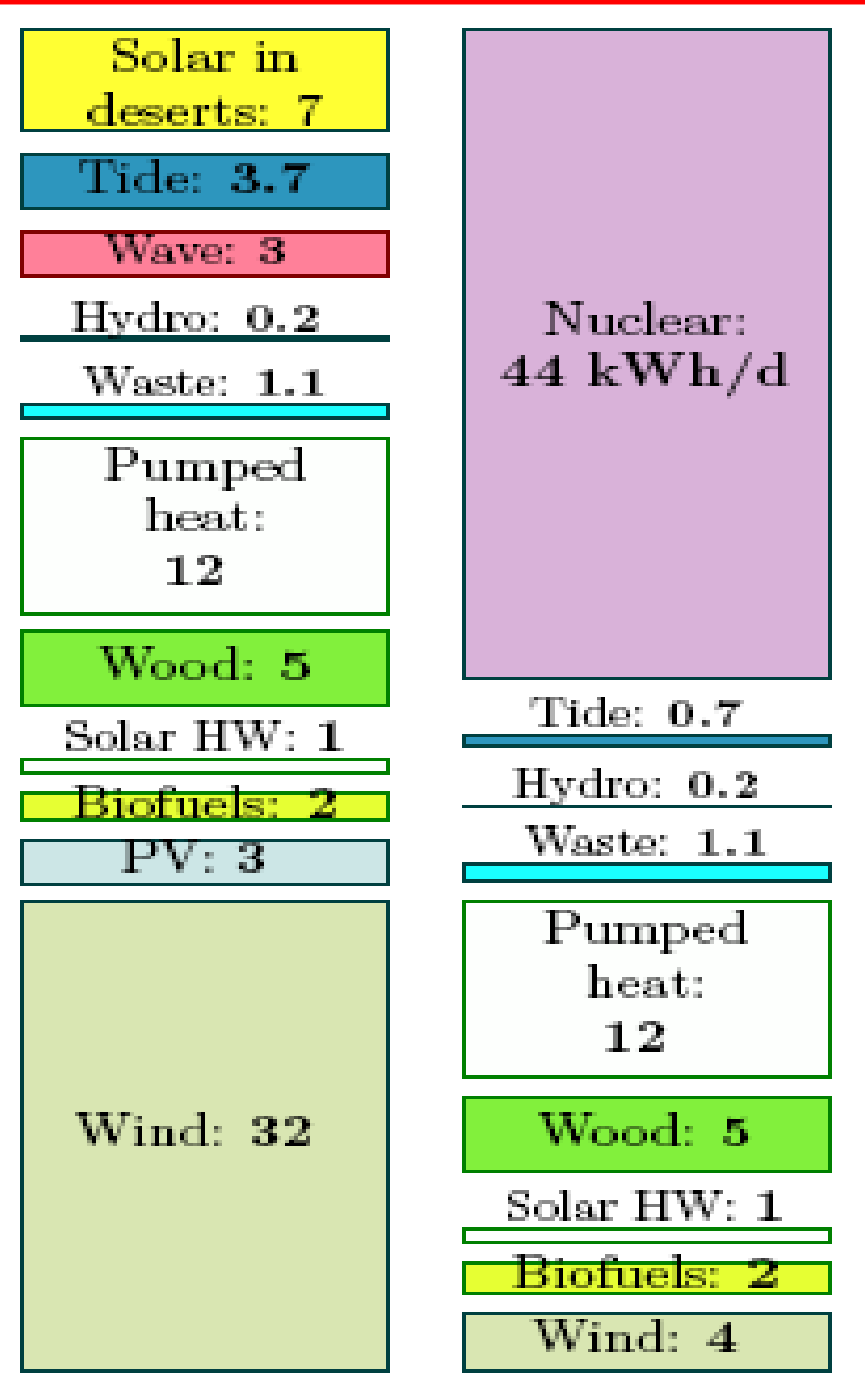

Diversity
NIMBY

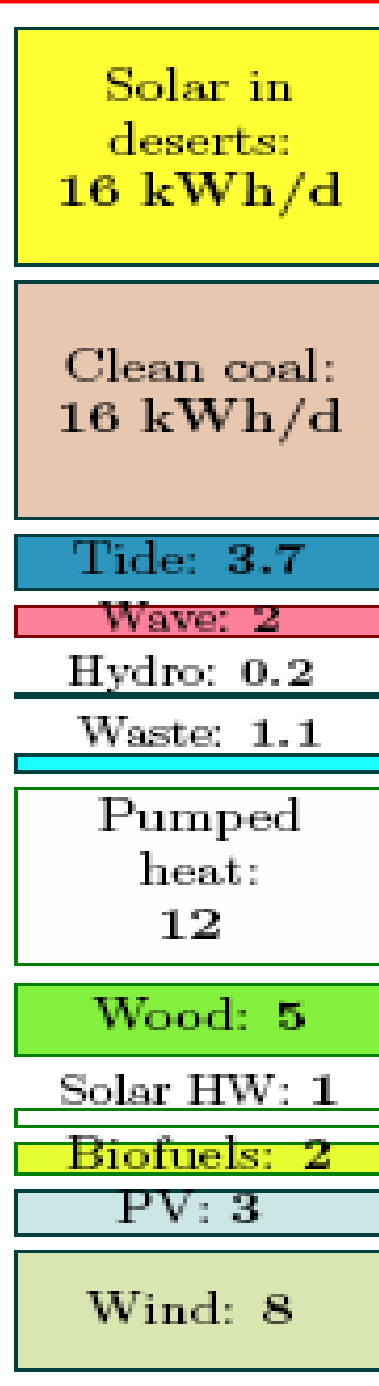

LibDem
Green

Economist 


\section{Emerging concepts}

\section{Embedding supply within a micro-grid}

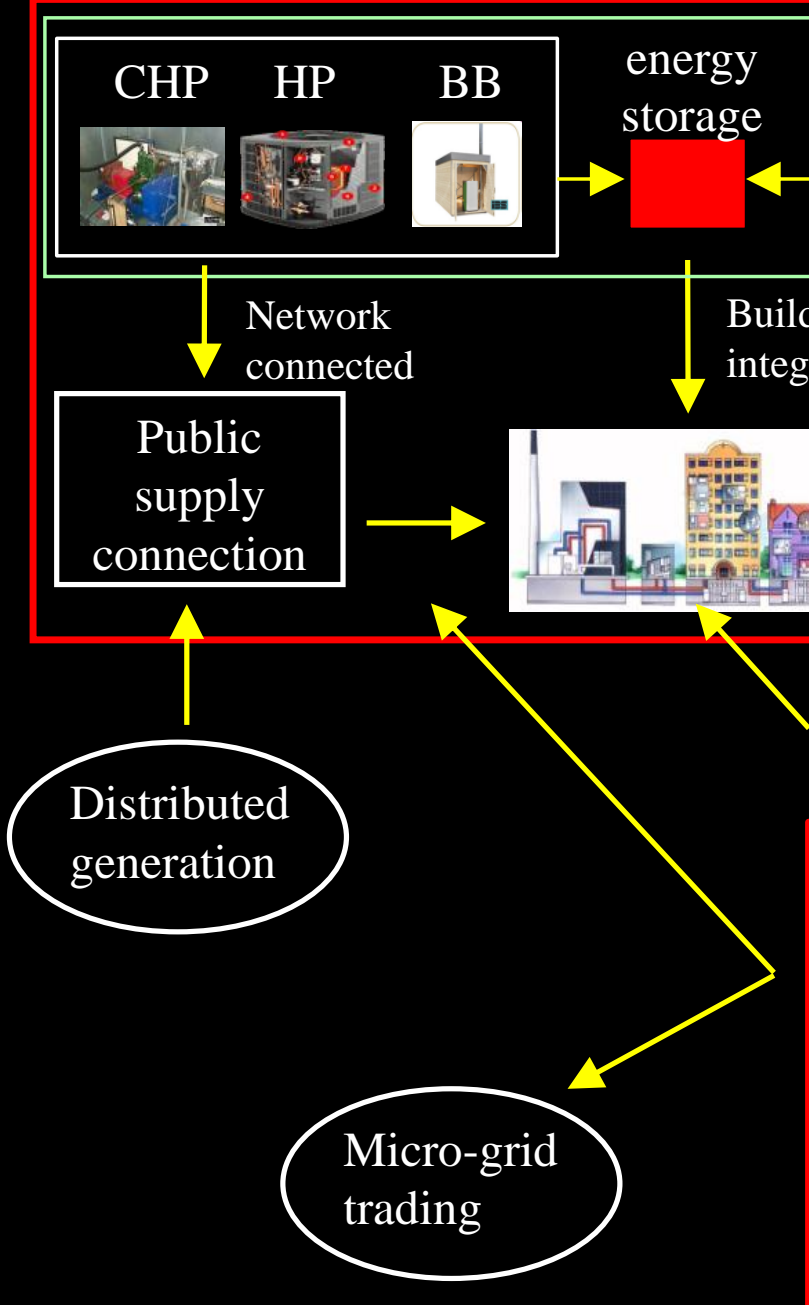

Power station

Wind

Marine

CHP

Urban RE

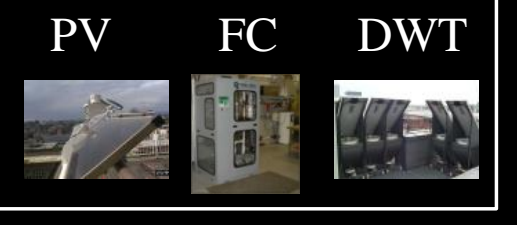

Building integrated

Renewable energy systems 3-5 times larger if the requirement is to match energy production.

\section{Internet-enabled energy services}
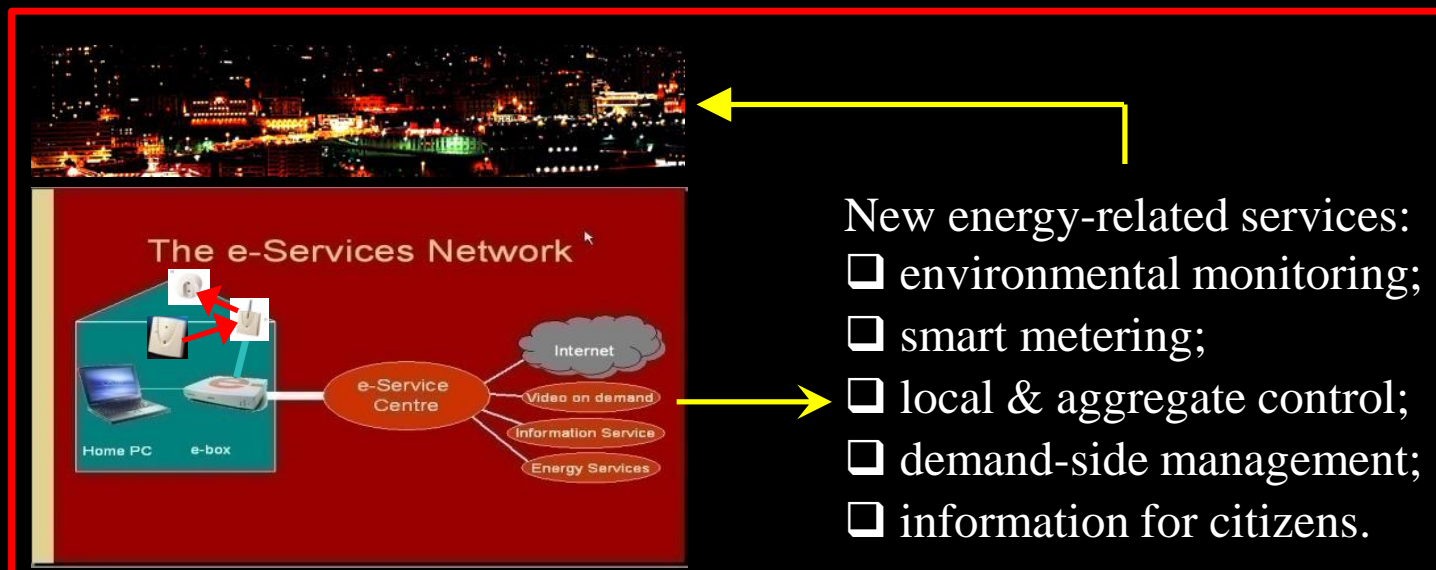


\section{The Lighthouse Building, Glasgow}

Demand reduction through

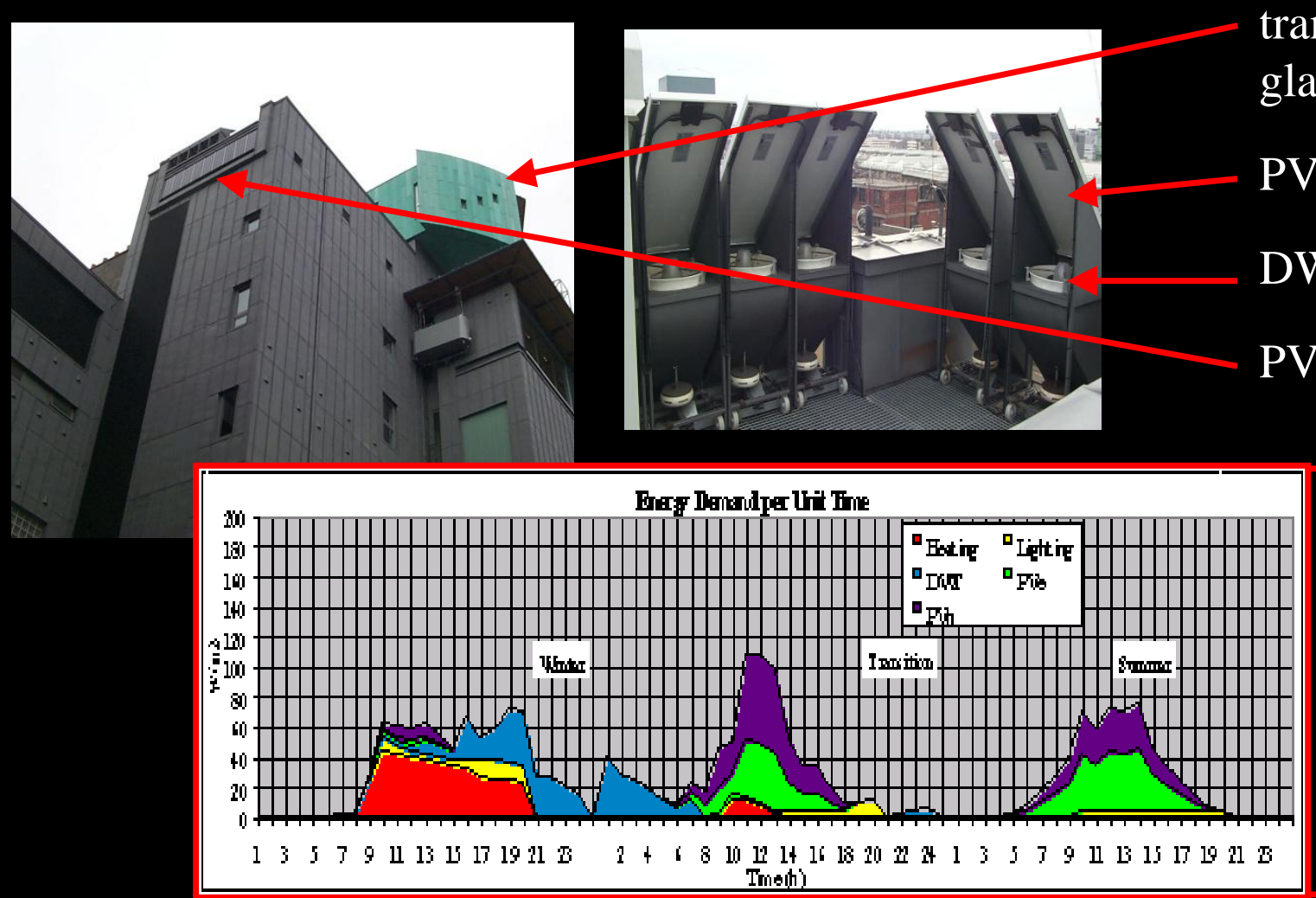

total demand: $68 \mathrm{kWh} / \mathrm{m}^{2} \cdot \mathrm{yr}$

total RE supply: $98 \mathrm{kWh} / \mathrm{m}^{2} . \mathrm{yr}$

Challenges:

$\square$ accommodate the grade, variability and unpredictability of energy sources/demands;

$\square$ hybrid systems design;

$\square$ strategies for co-operative control of stochastic demand and supply;

$\square$ network balancing, fault handling and power quality maintenance. 


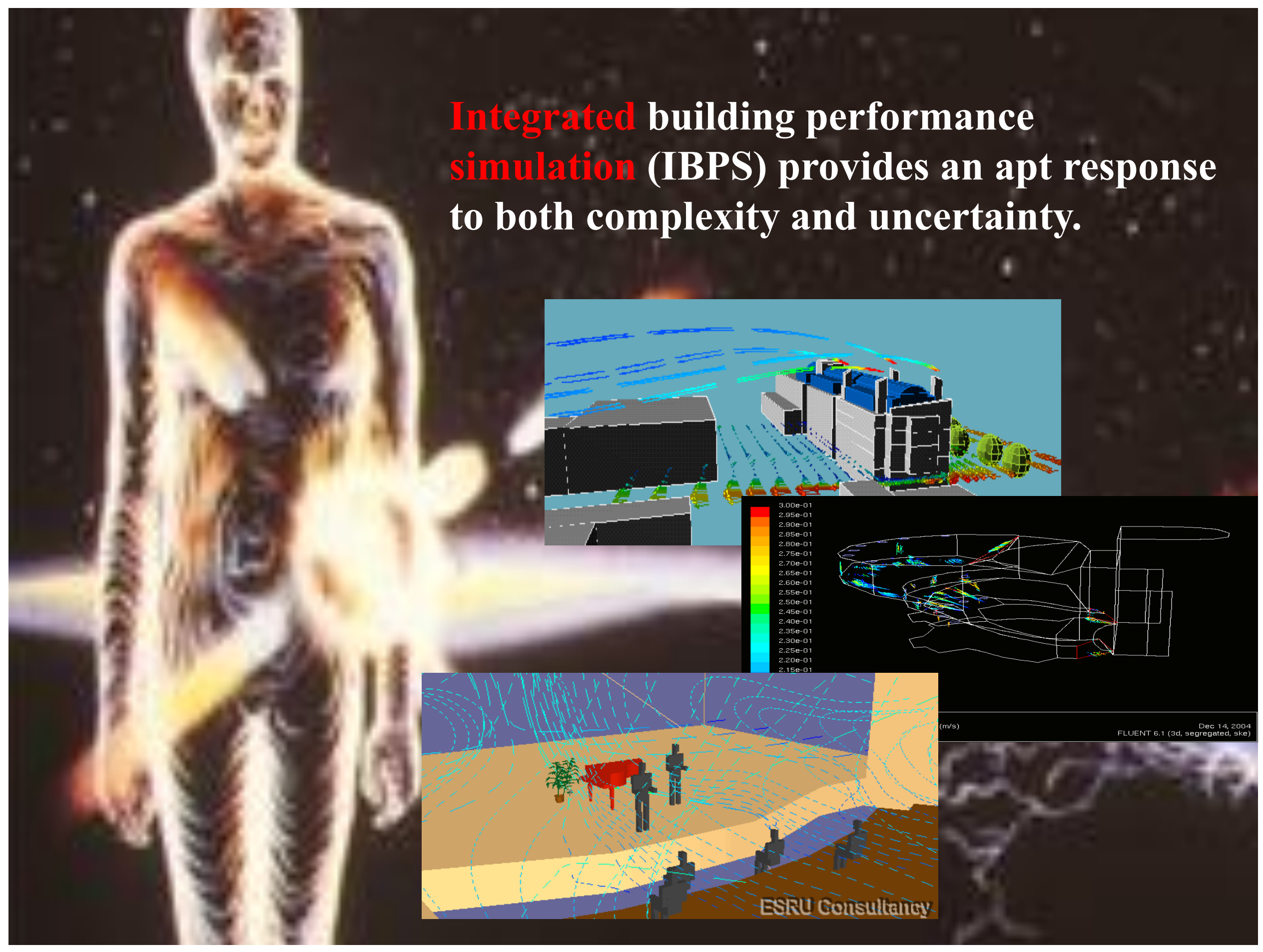




\section{Decision-support}

Most design decisions are ill-informed.

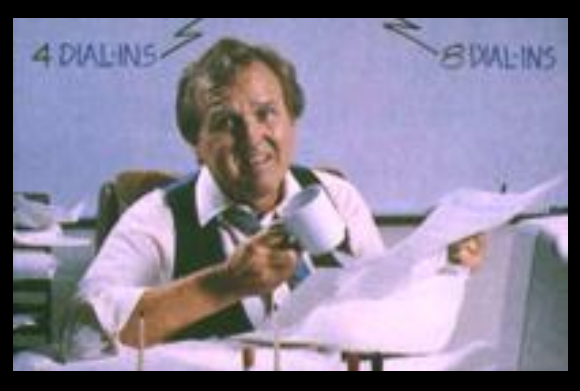

Energy systems are dynamic, non-linear and systemic.

A computational approach to

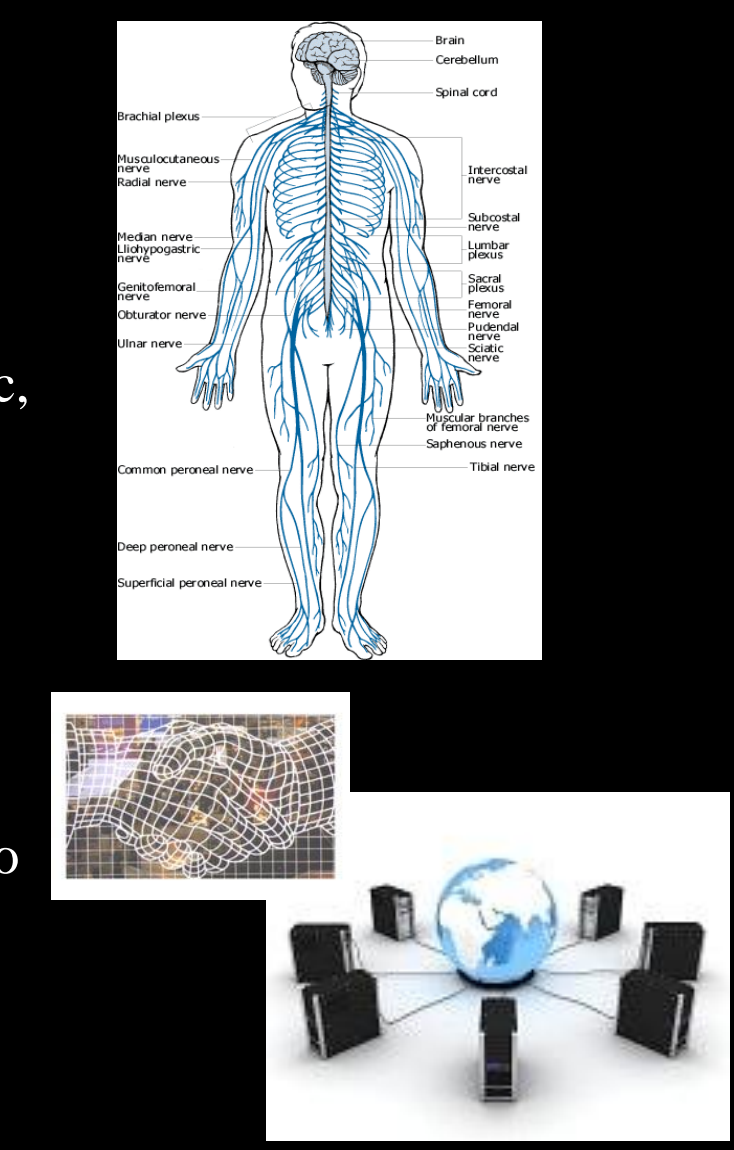

design provides a solution
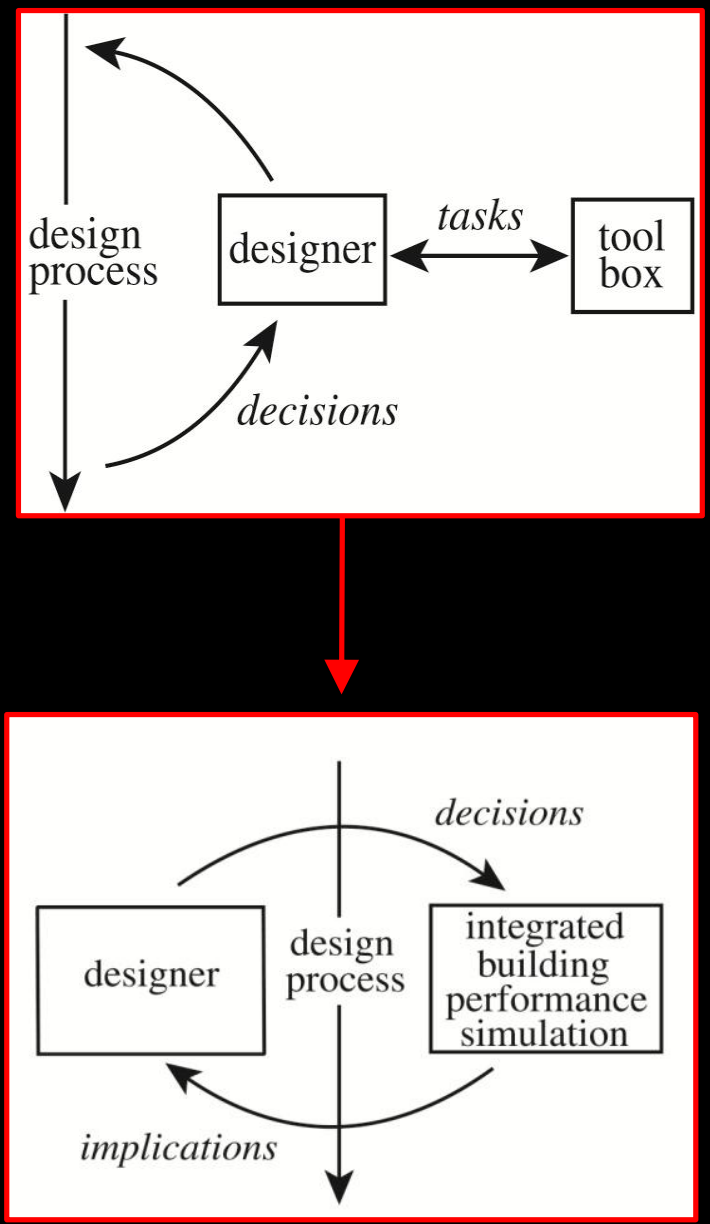

The aim is to embed advanced design tools in businesses. 


\section{DECC: 2050 calculator}

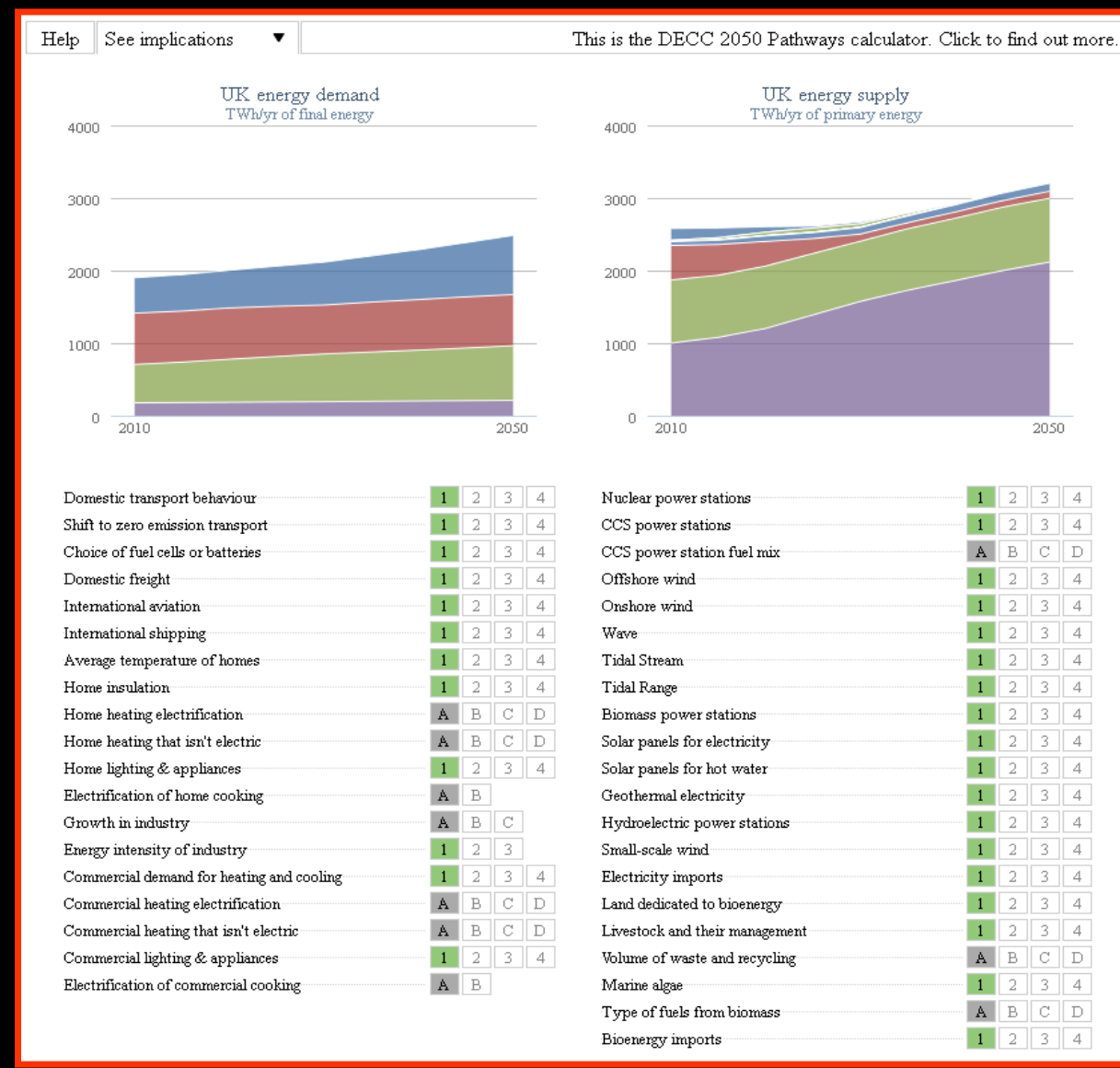

http://withouthotair.blogspot.com/2010/07/2050-calculator-tool-at-decc.html

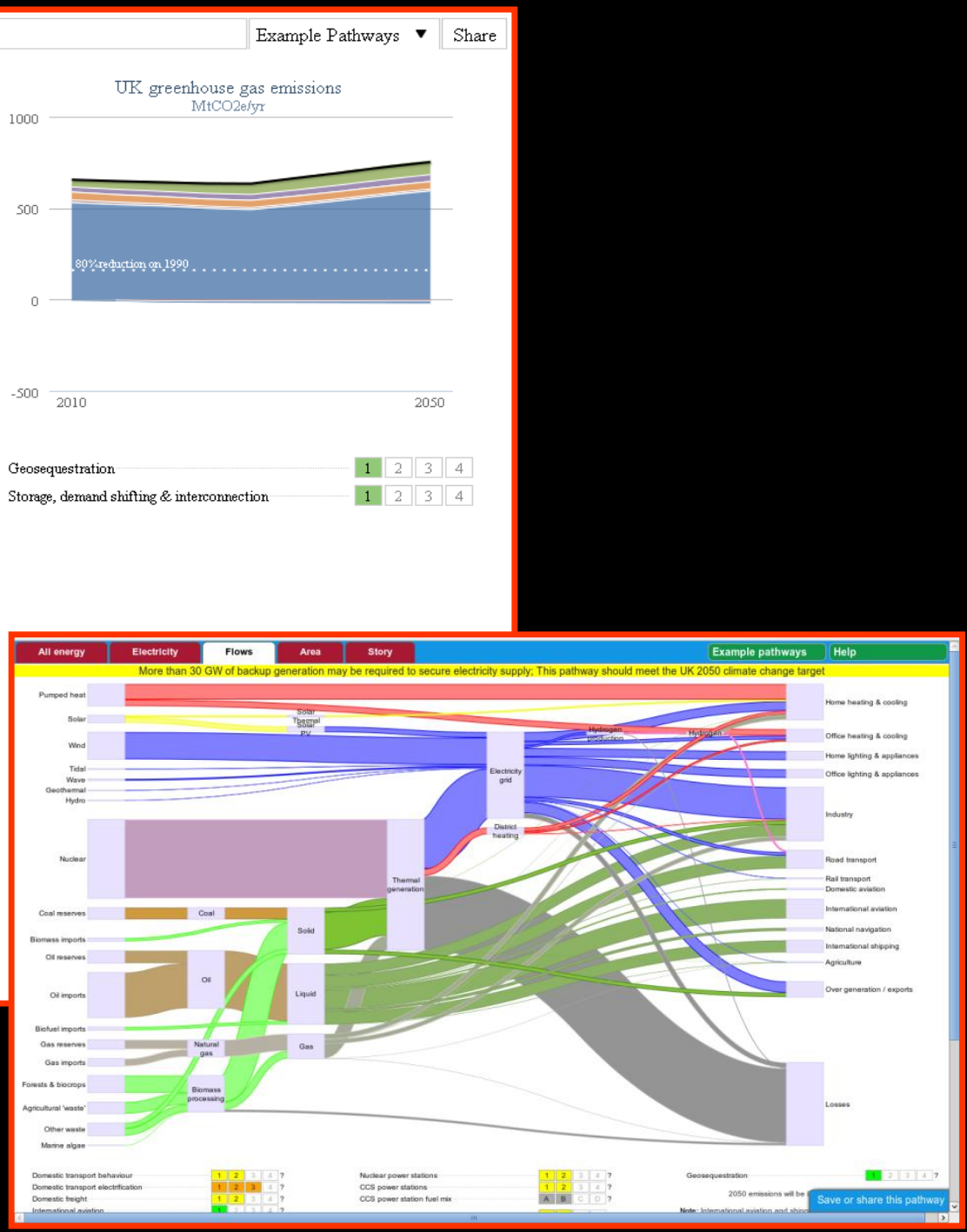




\section{EnTrak: energy management and action planning}
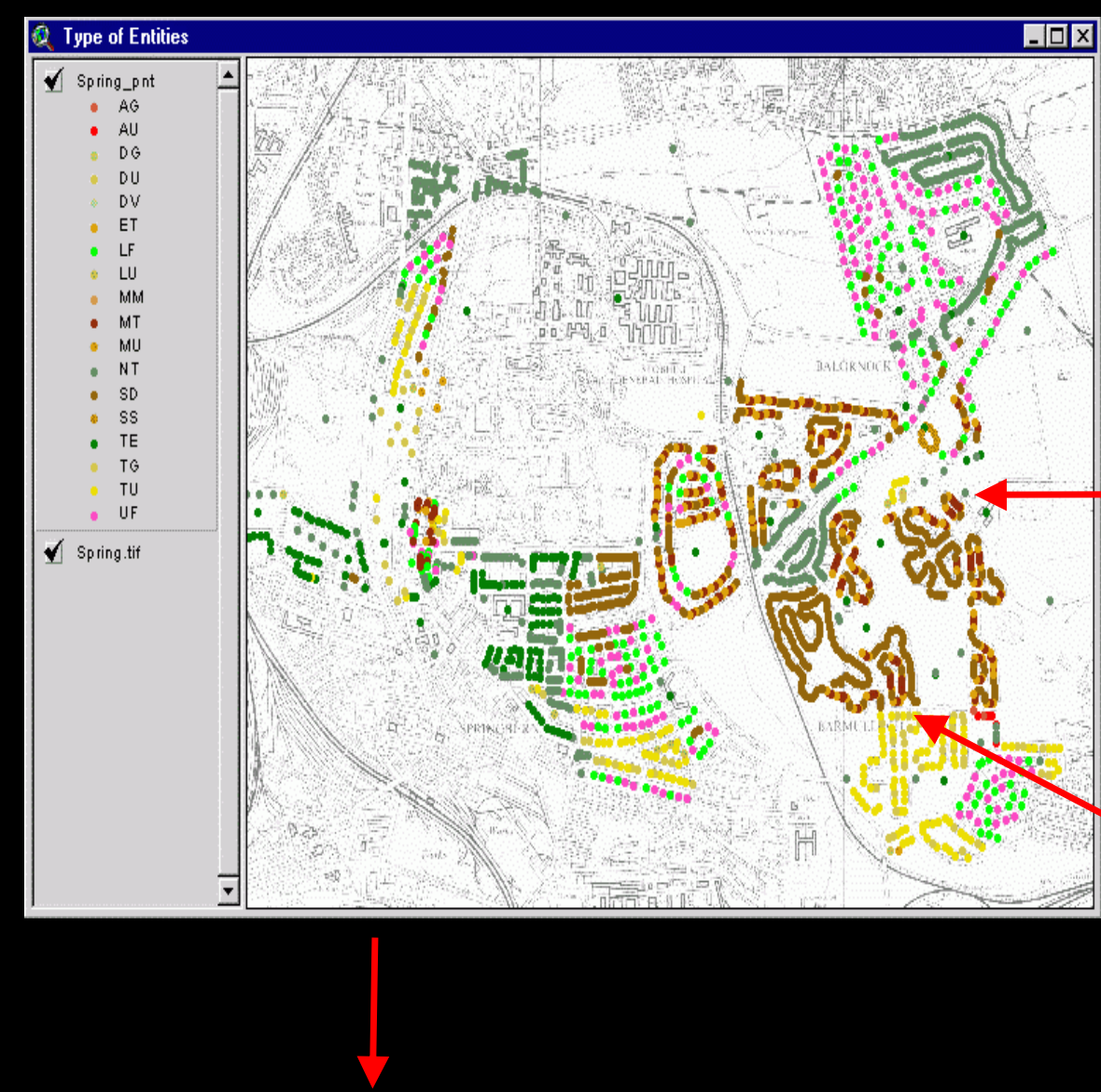

consumption \& emissions monitoring; city profiling \& property classification; trend analysis \& action planning

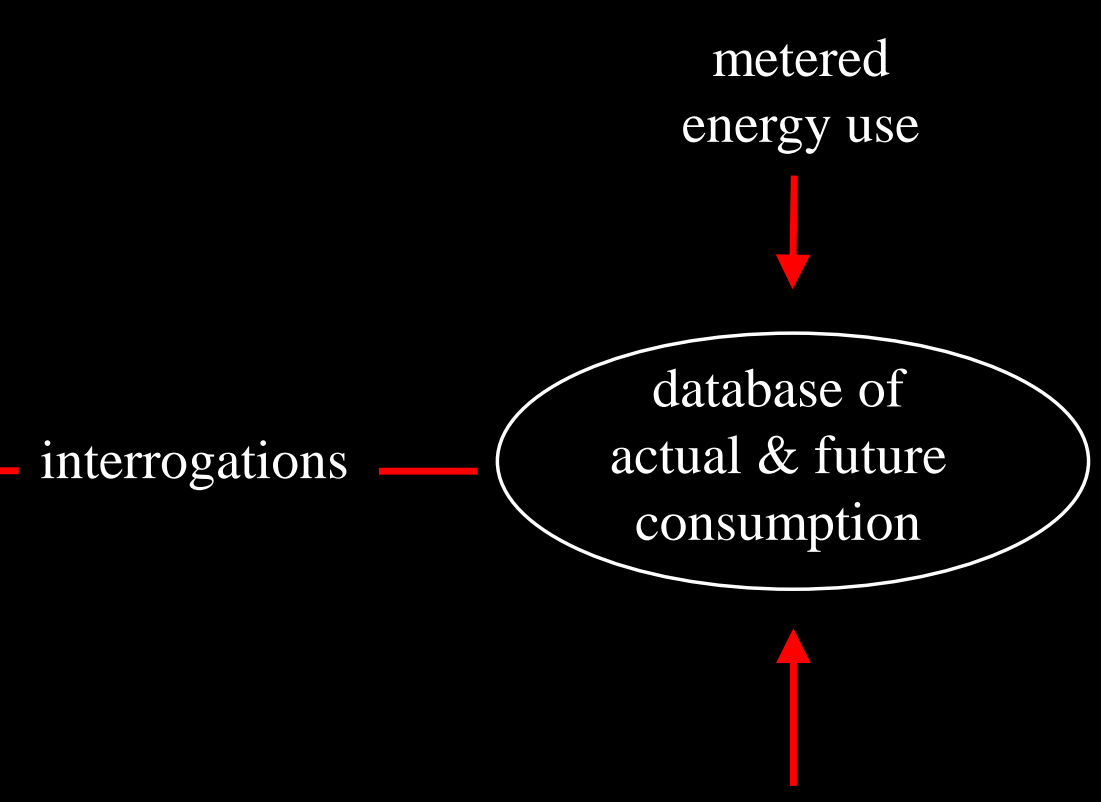

scenario simulations

e-services

information for government, local authorities, institutions, industry, utilities, designers, planners, citizens and others 


\section{Urban planning study}

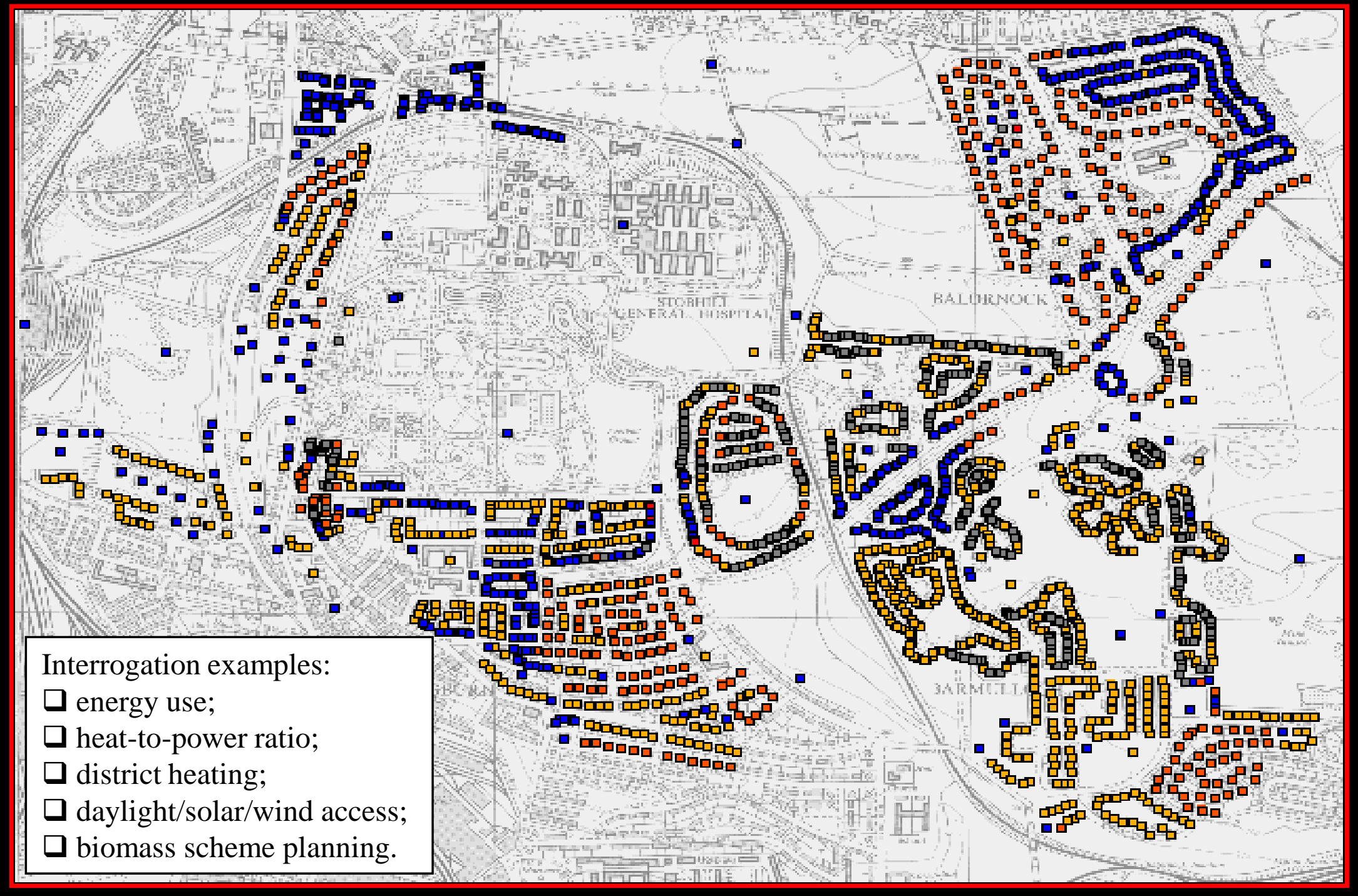




\section{Regional planning: SRO wind farm consent}
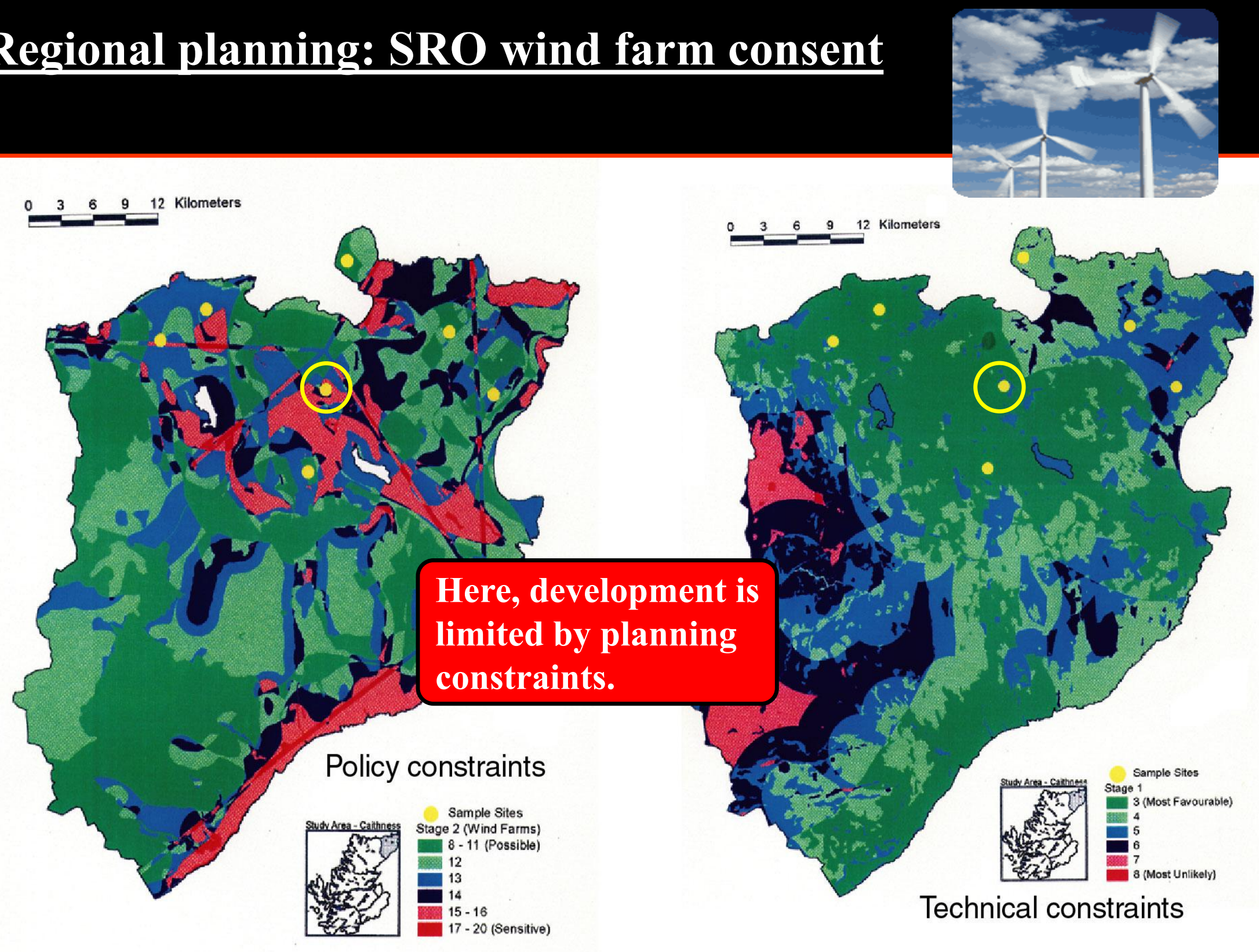


\section{Merit: matching supply to demand}

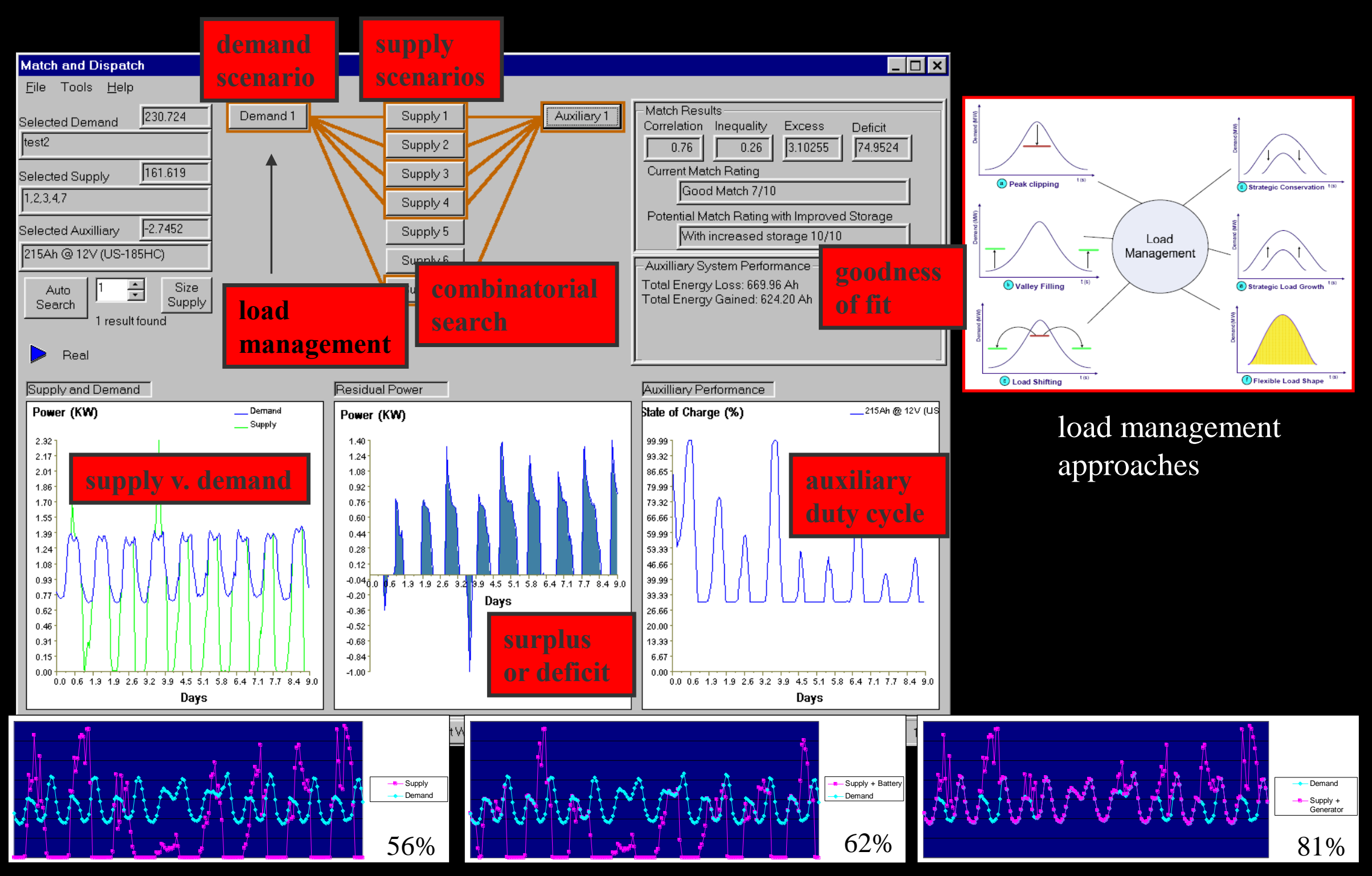




\section{Micro-grid options to improve demand/supply match}

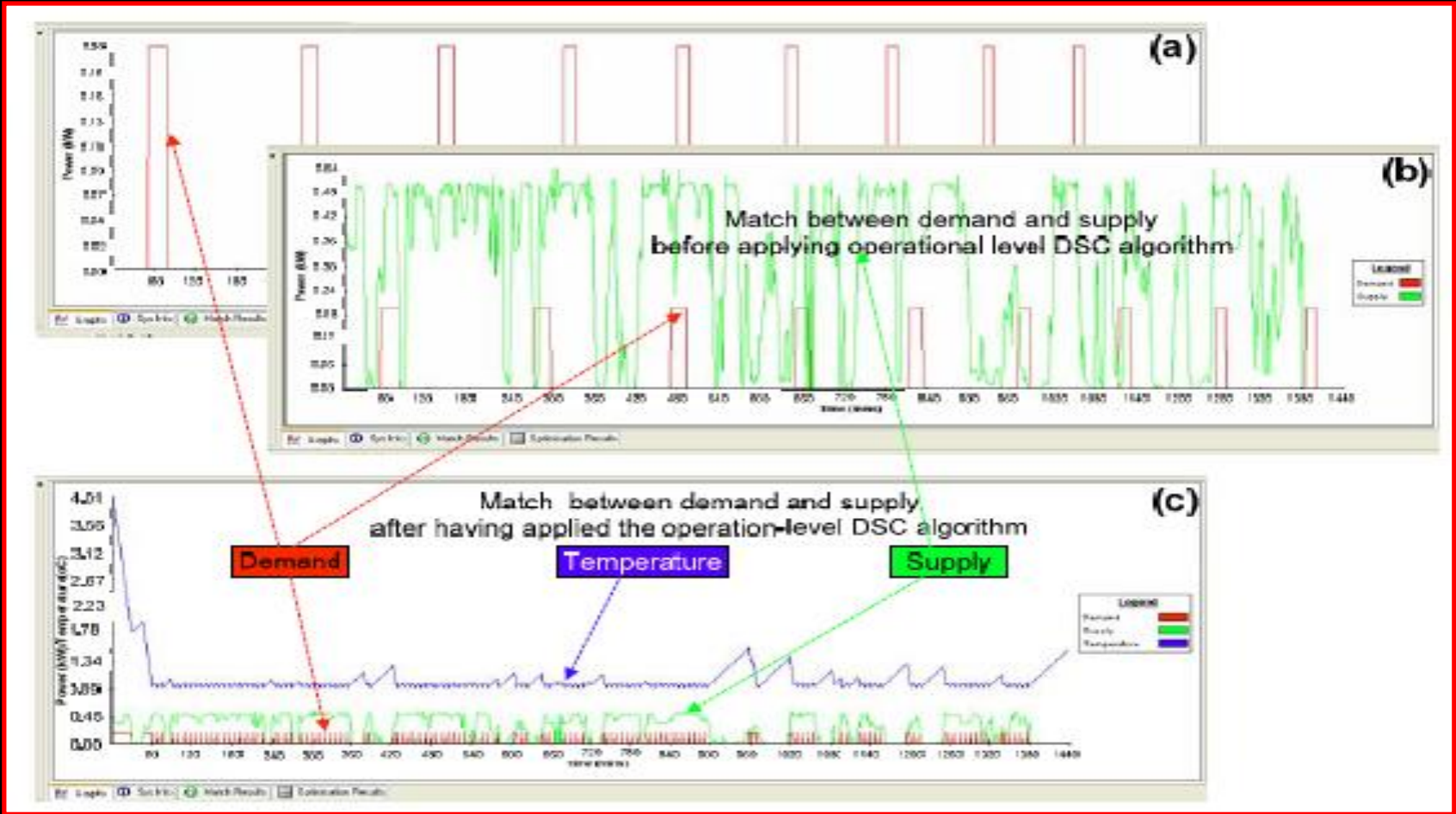

In absence of local storage, not possible to maintain a demand/supply match over time.

Options: use national grid and/or inter-connect MGs to allow trading of energy surpluses/deficits.

$\square M G T$-s program developed to examine the impact of governing parameters on criteria relating to MG trading performance. 


\section{Energy systems simulation}
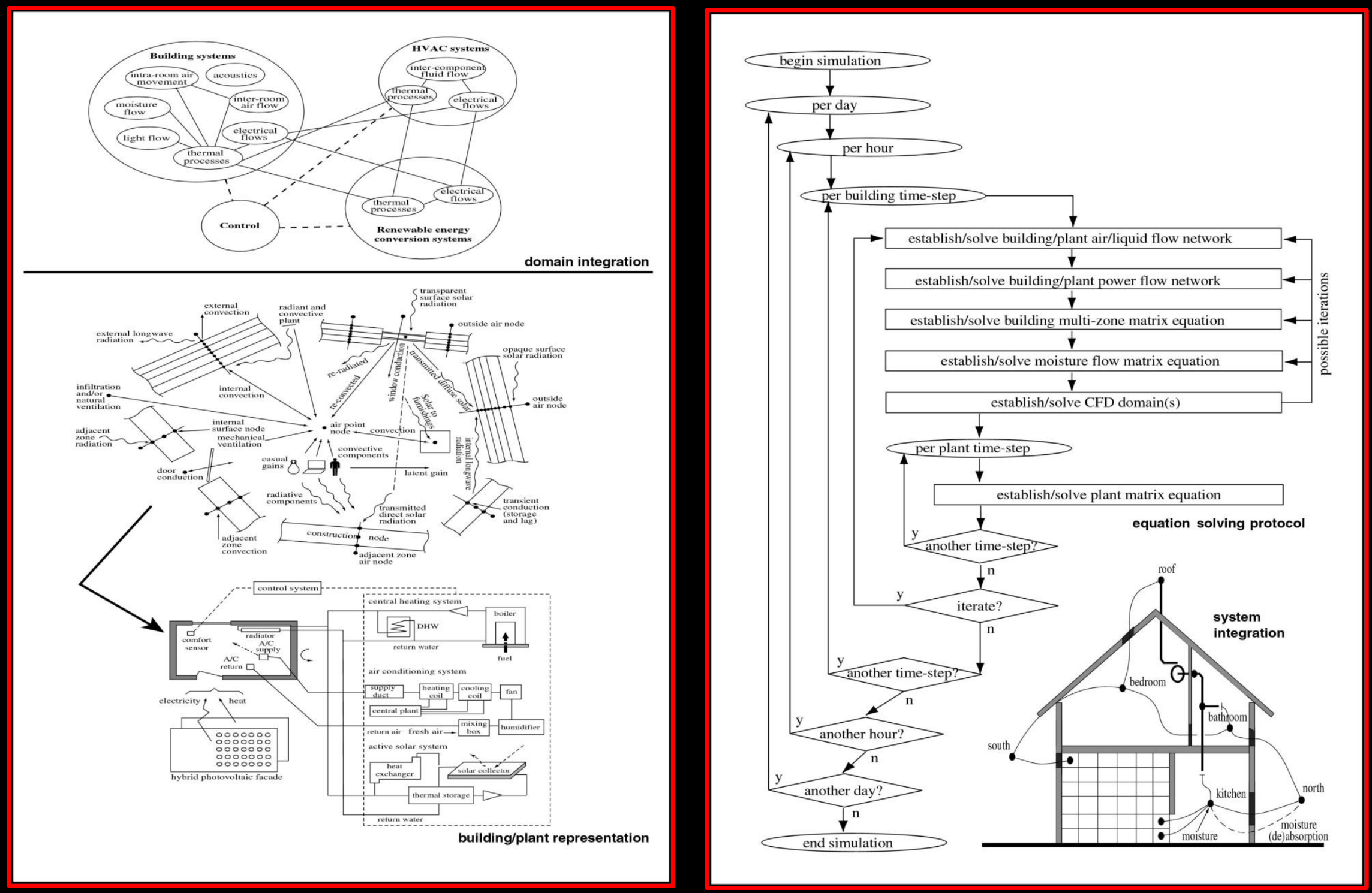


\section{Systems characterisation}

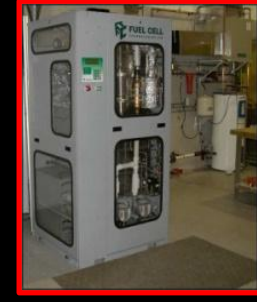

fuel cell
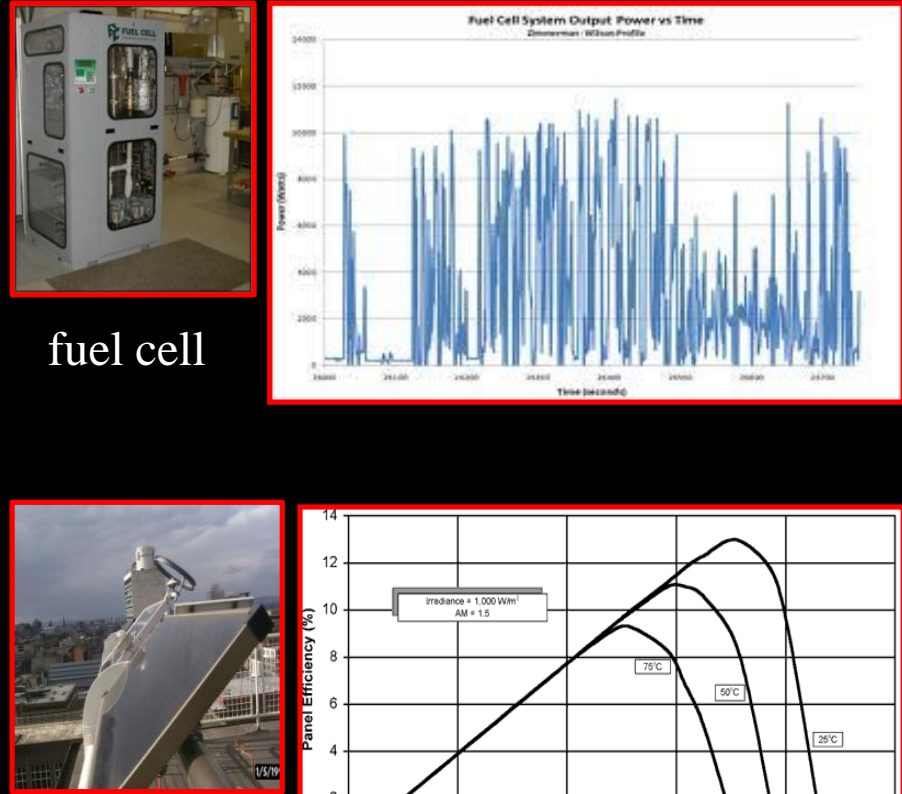

photovoltaics
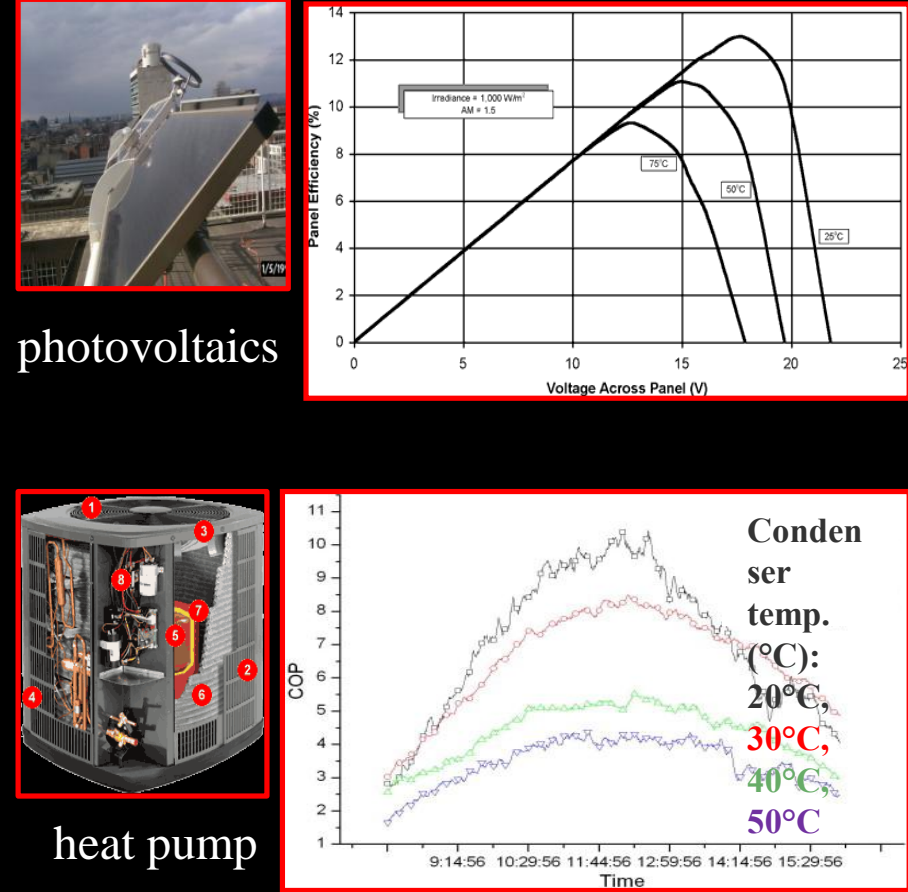

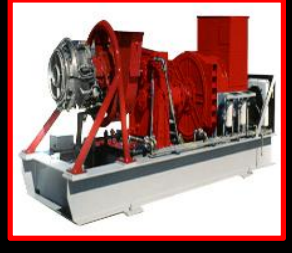

gas turbine
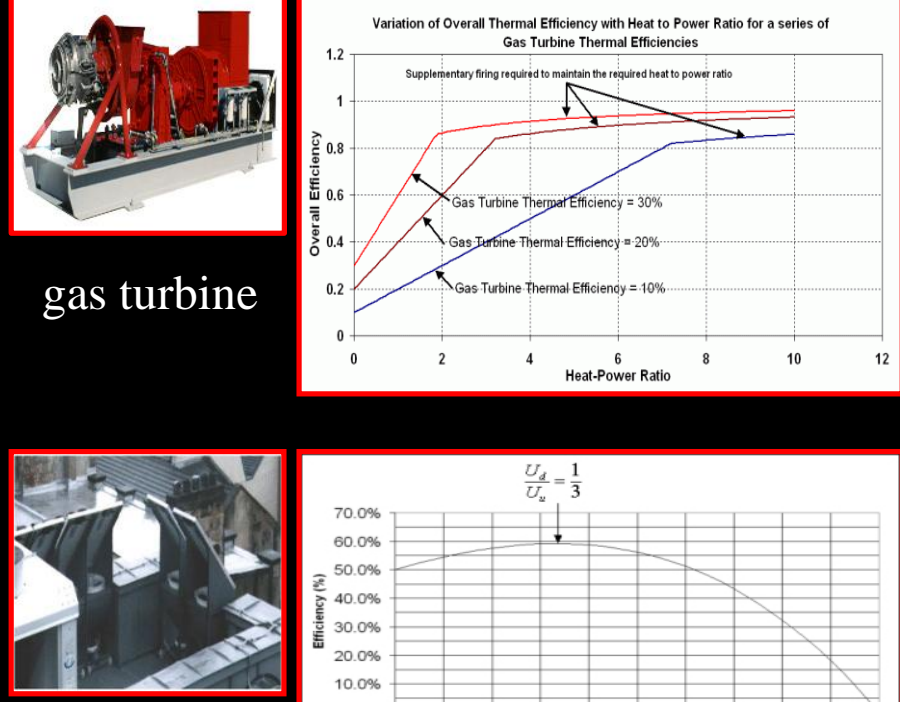

wind turbine

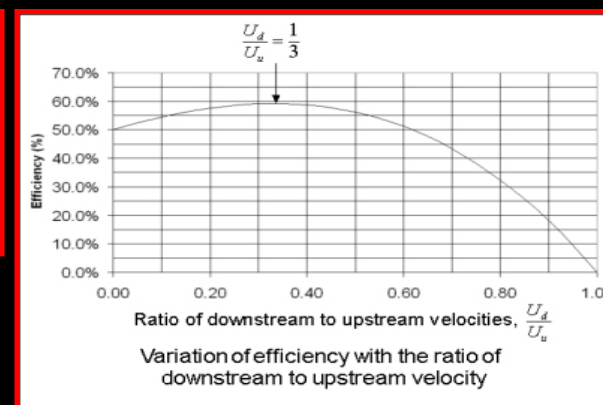

downstream to upstream velocity

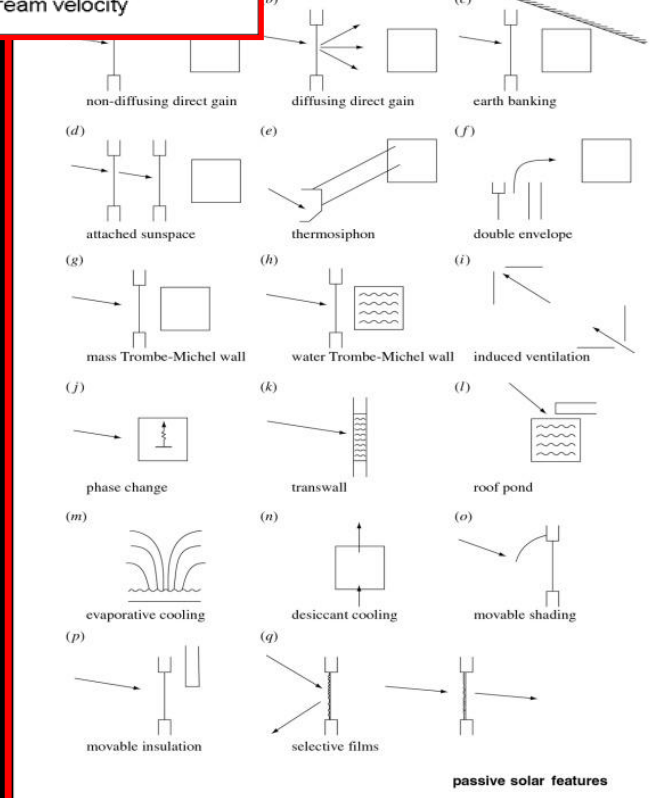




\section{IBPS development goals and progress}

High integrity representation of the dynamic, connected and non-linear physical processes that govern the different performance domains that impact each other and the overall acceptability of buildings, new or existing.

$\square$ Good progress with fundamental process representation.

$\square$ Need for formal research into acceptable levels of abstraction.

Developments: air movement, light distribution, moisture flow, occupant behaviour, fuzzy logic, exergy, uncertainty, new supply systems, smart control, microgrids, adaptive materials, fast solvers, enhanced geometry etc.

Performance domain conflation to represent the interactions and conflicts that occur between problem parts and thereby give rise to the need to make performance trade-offs and accept non-optimum solutions overall.

$\square$ Good progress with coupling of principal domains.

Need for formal research into domain interactions.

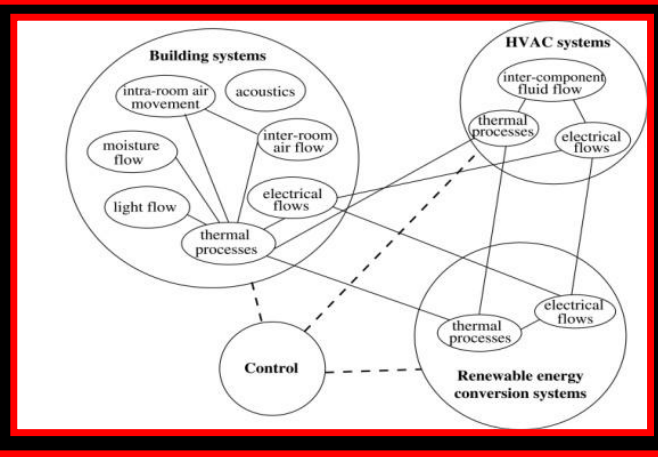

Design process integration to embed high fidelity tools within work practices in a manner that adds value and, in the long term, supports virtual design through the interactive manipulation of a design hypothesis with performance feedback in real time.

$\square$ Good progress with data and process representation mechanisms. $\square$ Need for formal research into design process adaptation.

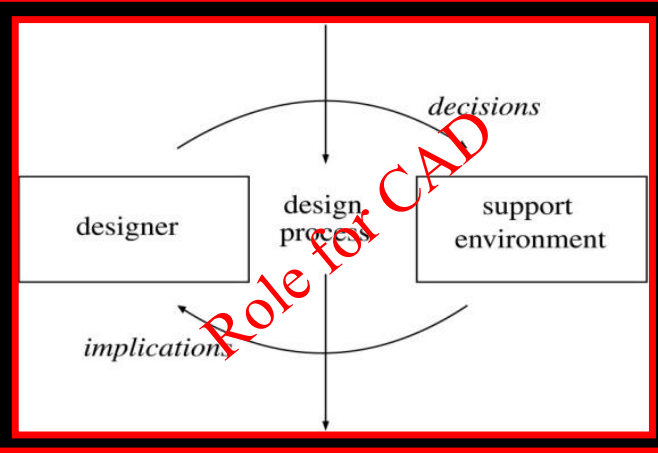




\section{IBPS: cheaper, quicker and better}

Helps practitioners to:

ensure requisite levels of thermal, visual \& acoustic comfort;

attain indoor air quality, health \& productivity goals;

$\square$ reduce operational and embodied energy;

$\square$ lessen environmental emissions and impacts.

$\square$ ensure systems controllability and in-built digital intelligence;

$\square$ incorporate innovative EE \& DSM solutions;

$\square$ embody high levels of new and RE technologies;

$\square$ conform to legislative requirements;

$\square$ facilitate participation in future 'smart' grids.

Defines a new best practice:

$\square$ respects temporal aspects and interactions;

$\square$ integrates all technical domains;

$\square$ supports co-operative working;

$\square$ enables realistic life cycle assessments;

$\square$ links building design to local and global issues.

The approach is rational:

$\square$ gradual evolution of the problem description;

$\square$ action taken against performance outputs at discrete stages.

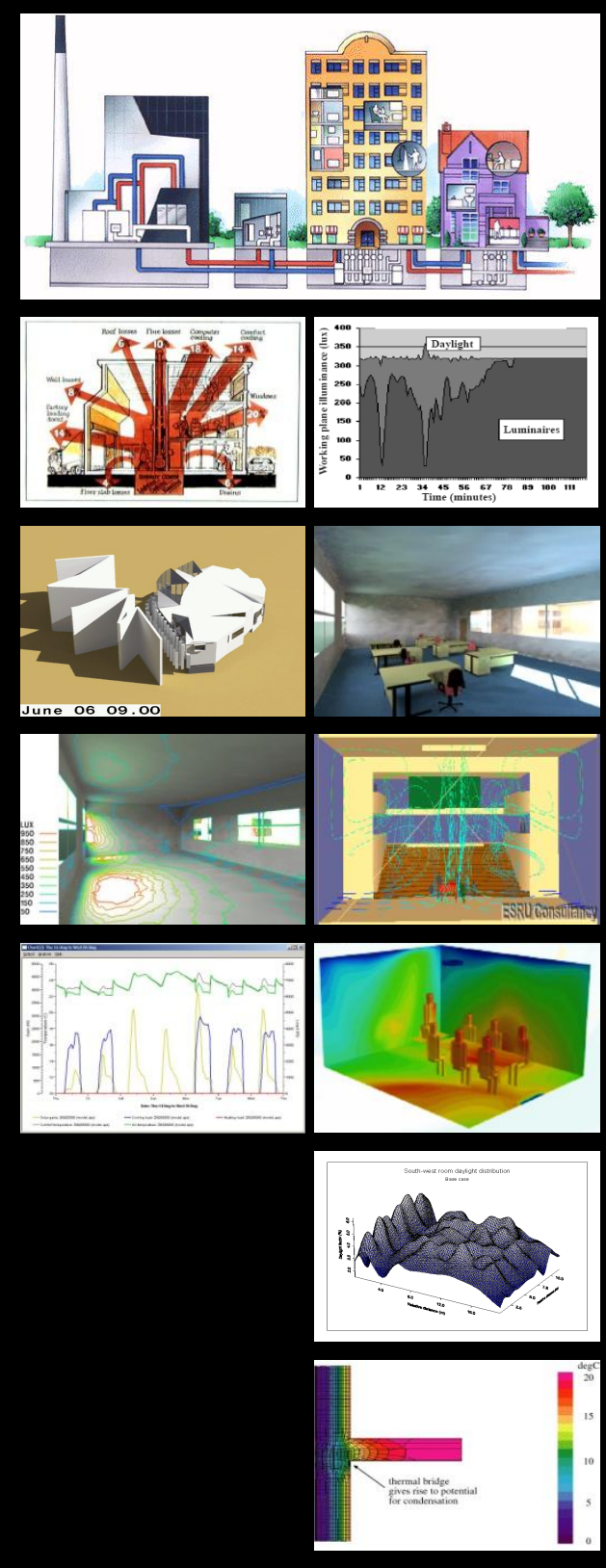




\section{Behaviour follows description (i.e. reward follows effort)}

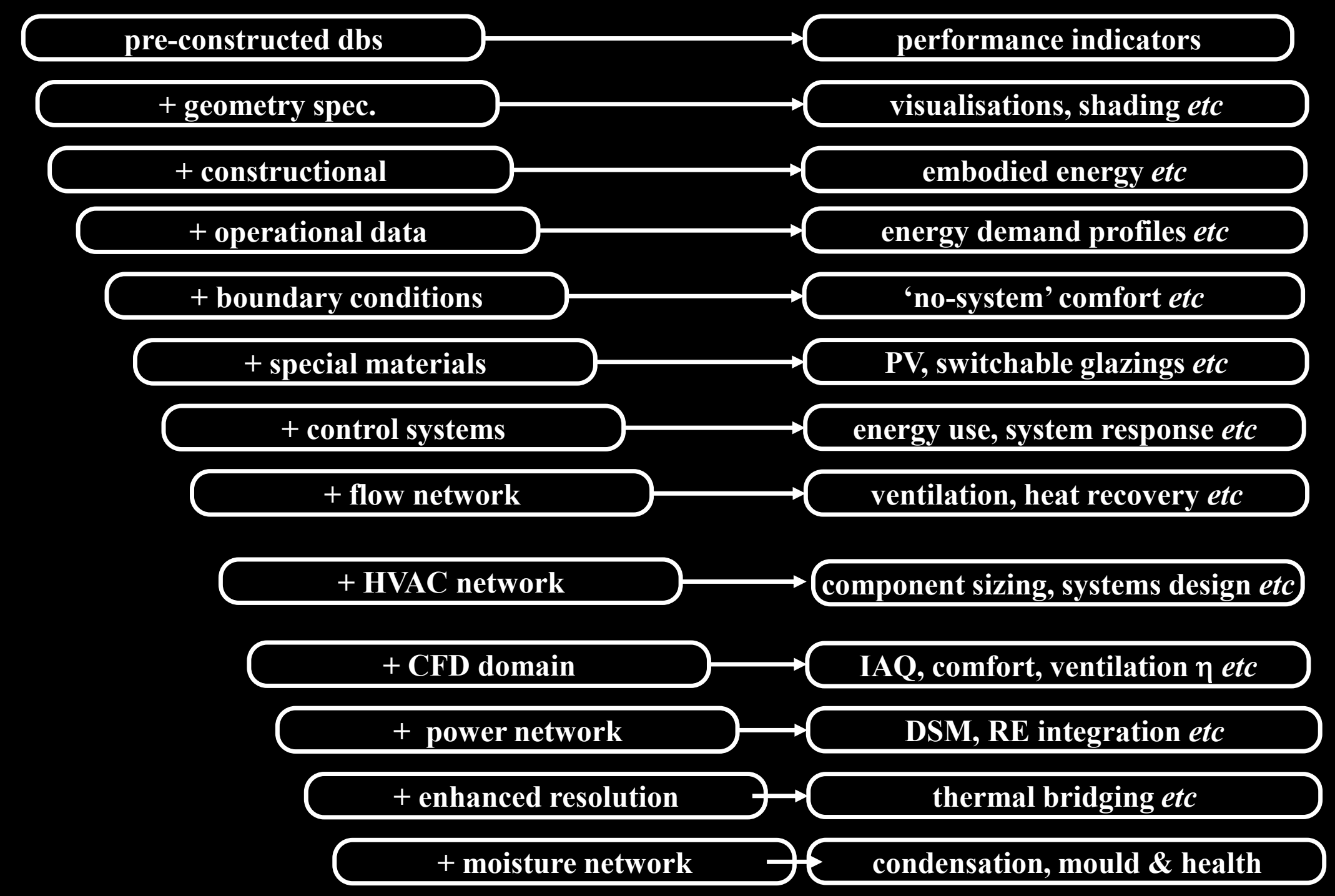




\section{Quantifying the effects of uncertainty}

ㅁ. External approach

- alters only the input data

- requires multiple simulations and analysis of differences in predictions

- differential method alters one parameter at a time and requires $2 \mathrm{P}+1$ simulations for $P$ uncertain parameters

- factorial method alters groups of parameters to quantify interactions between and requires $2 \mathrm{P}$ simulations

- Monte Carlo method alters all parameters simultaneously to quantify the overall effect (number of simulations is independent of $\mathrm{P}$ and is typically $~ 80$ )

- to quantify individual contributions, interactions between contributions and the overall effect requires all three methods.

口 Internal approach

- Includes uncertainty within the simulation

- represents model parameters as a function of uncertainty (interval, fuzzy and affine arithmetic methods)

- requires only a single simulation to quantify individual and overall effects

- Uncertain parameters are represented by a polynomial comprising a mean value and individual uncertainty terms represented as interval numbers

- Specific performance instances are created in a post-simulation analysis by specifying value for each of the uncertainty terms. 
ESP-r: integrated performance simulation
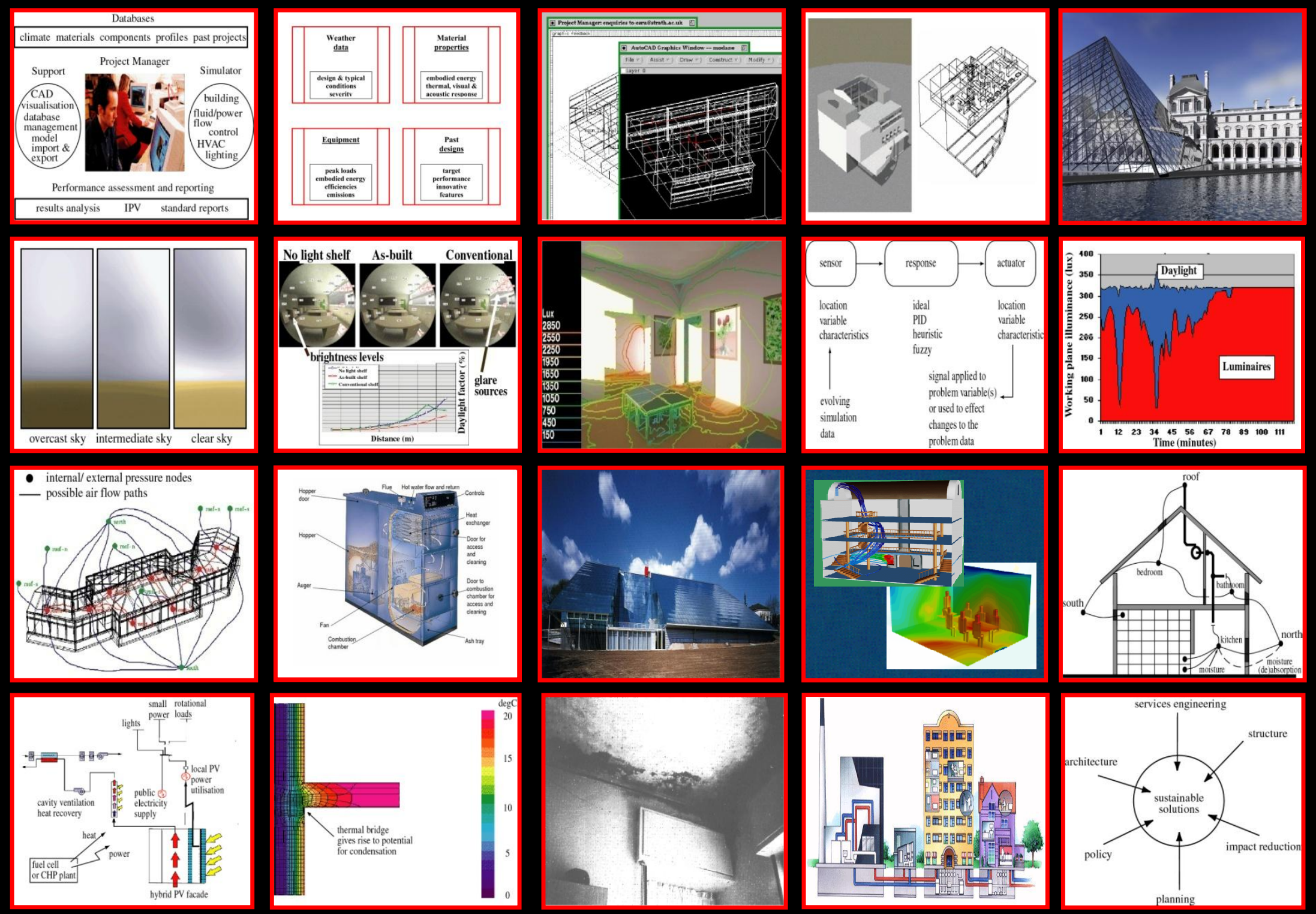


\section{Integrated views of performance}

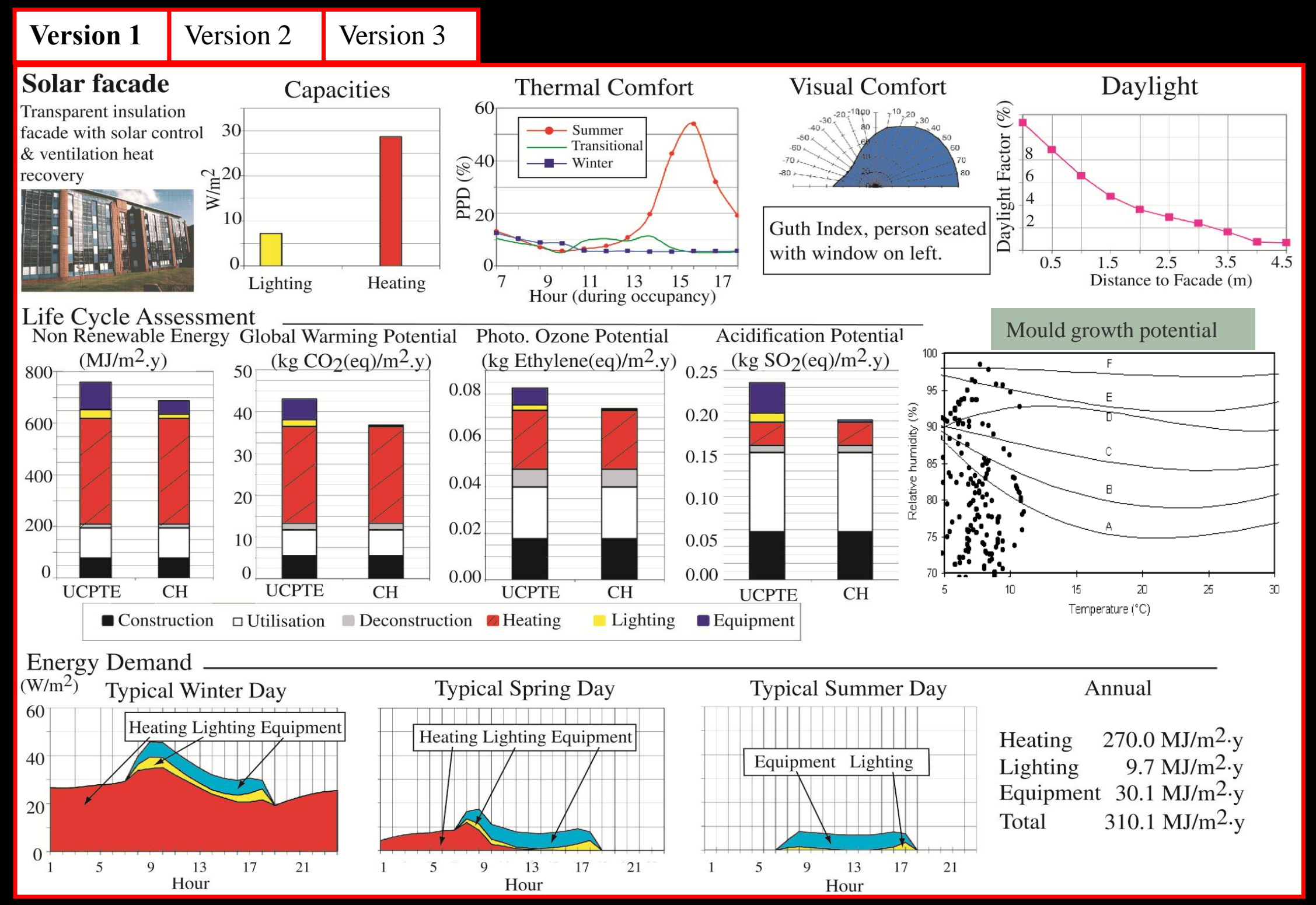



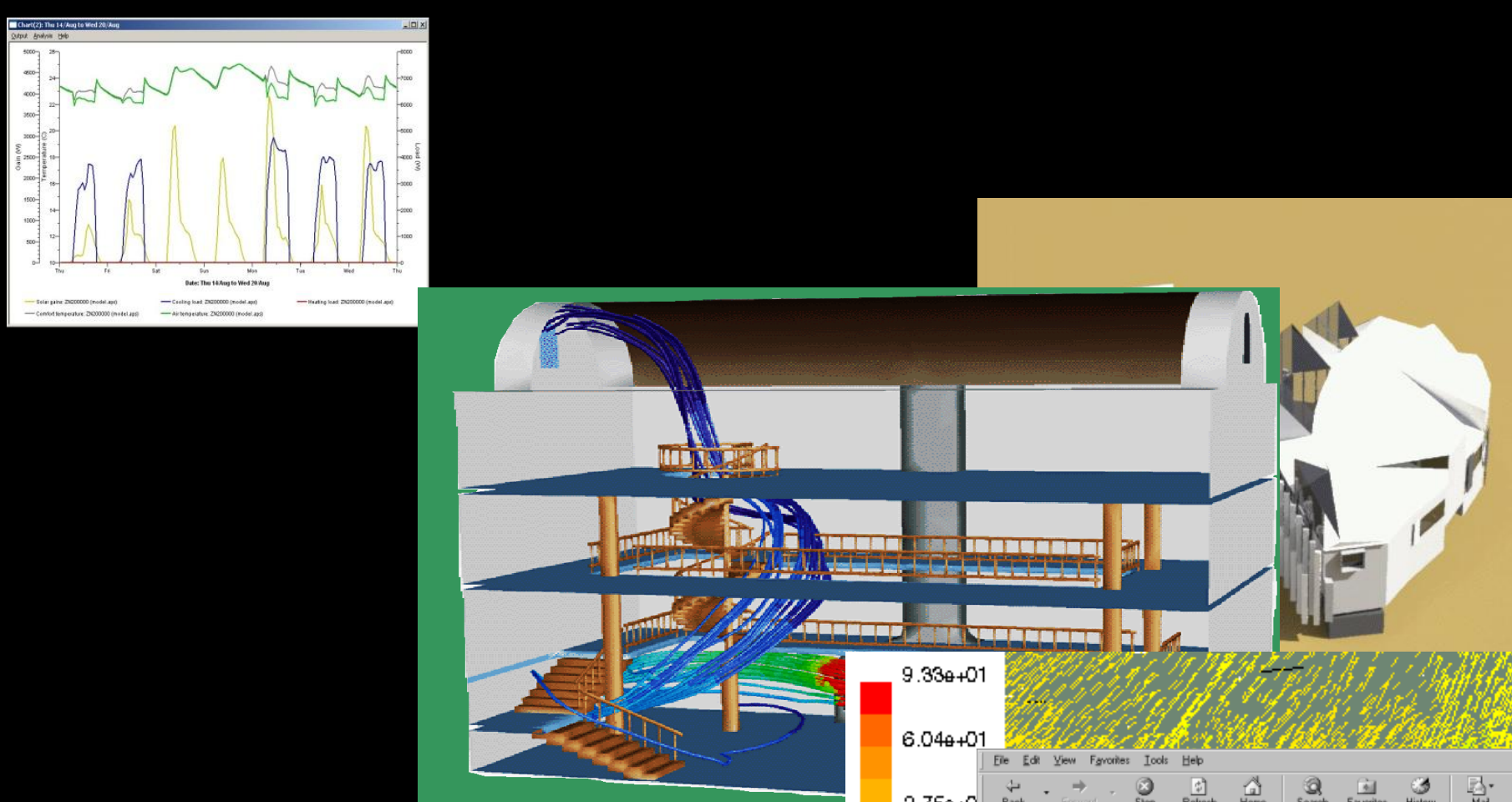

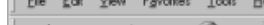

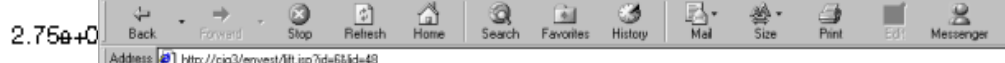

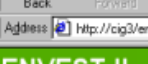

$-5.46 \theta+$ ENVEST II

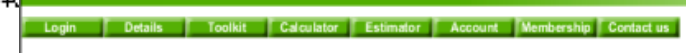

$-3.840+$

$-7.13++$

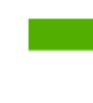

Environmental Impact

Structure Elements - Embodied

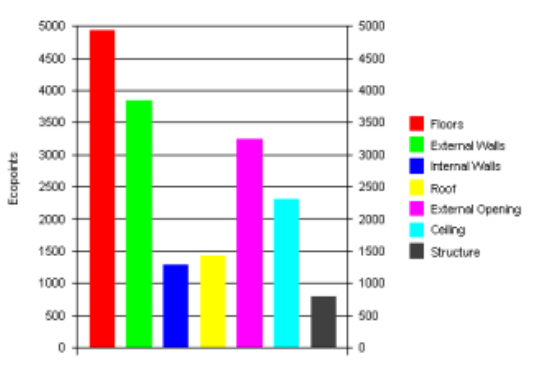




\section{An integrated views of performance}

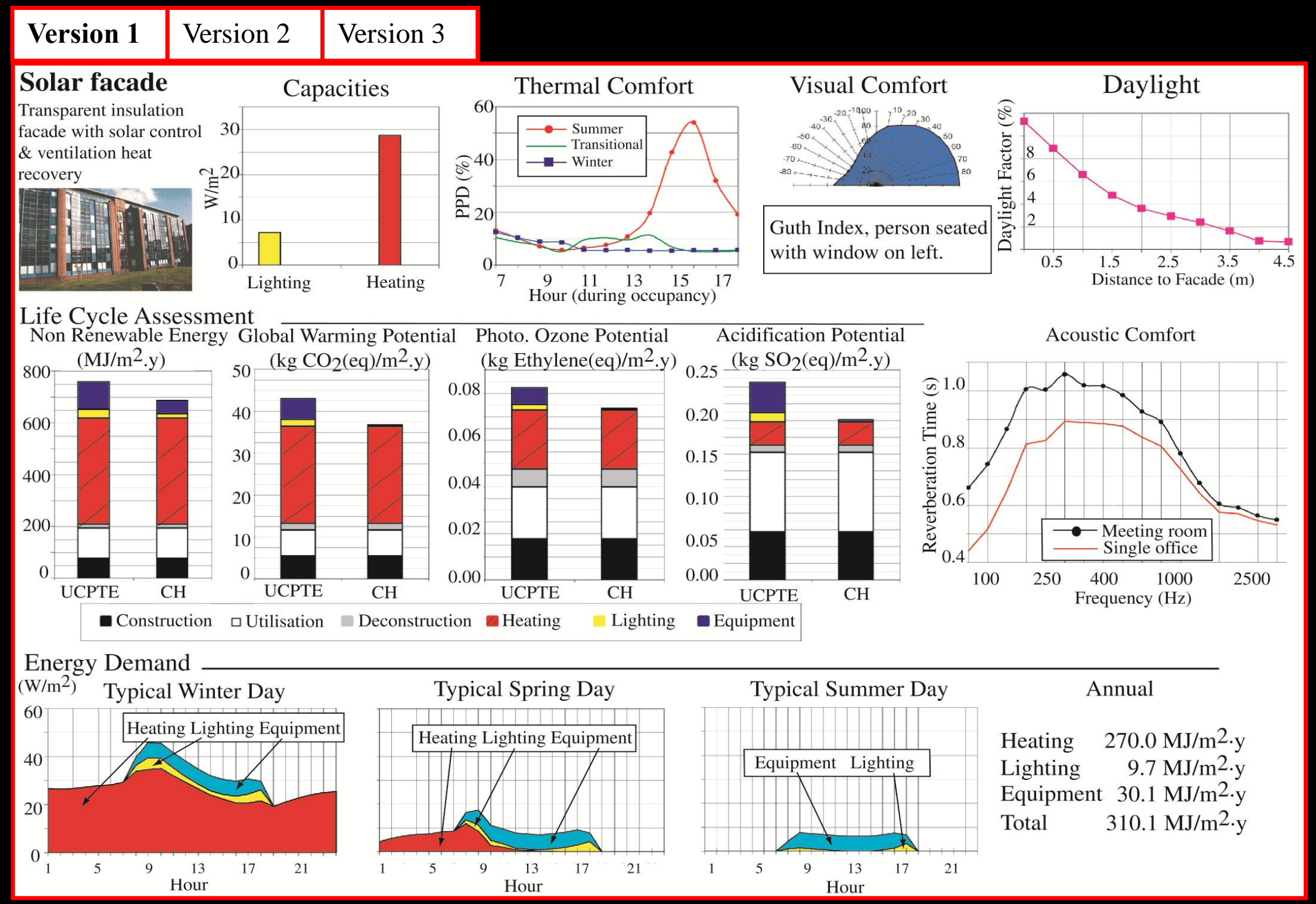




\section{Systematic investigation}

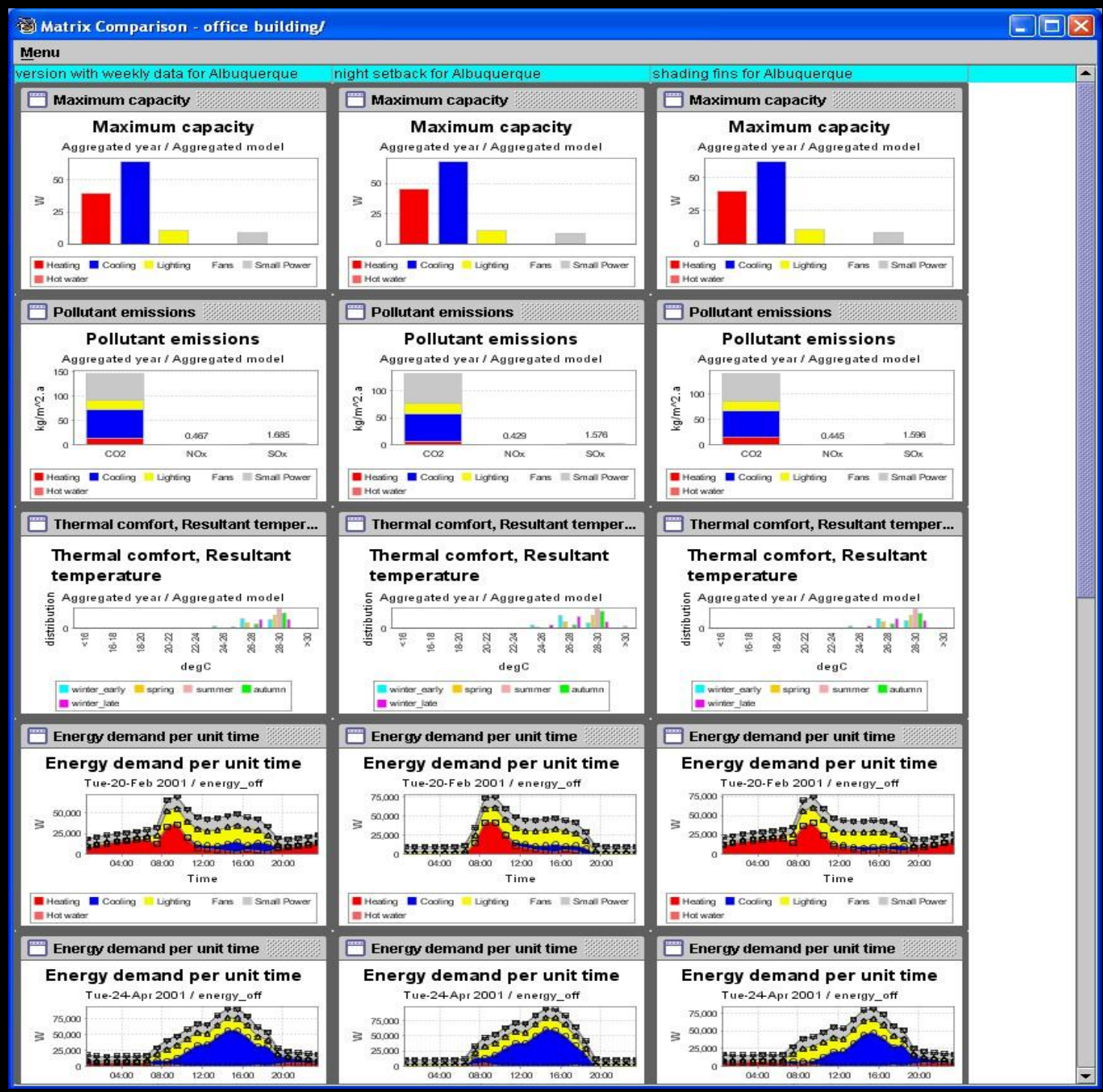




\section{Simulation-based design}

Requires adherence to a formal performance assessment method:

1. establish initial model for an unconstrained base case design;

2. calibrate model using reliable techniques;

3. assign boundary conditions of appropriate severity;

4. undertake integrated simulations using suitable applications;

5. express multi-domain performance in terms of suitable criteria;

6. identify problem areas as a function of criteria acceptability;

7. analyse results to identify cause of problems;

8. postulate remedies by relating parameters to problem causes;

9. establish reference model to required resolution for each postulate;

10. iterate from step 4 until overall performance is satisfactory;

11. repeat from step 3 to establish design replicability.

The time cycle of IBPS application is unacceptable in relation to the requirements of practice.

Attempts to address this by theoretical simplifications and/or reduced domain representation are ill-founded and unlikely to evolve the state-of-the-art in the direction required. 


\section{Simulation-based design evolution}

Requires changes to work practices and adherence to standard performance assessment methods (PAMs - action in red, knowledge in yellow):

1. establish initial model for an unconstrained base case design;

2. calibrate model using reliable techniques;

3. assign boundary conditions of appropriate severity;

4. undertake integrated simulations using suitable applications;

5. express multi-domain performance in terms of suitable criteria;

6. identify problem areas as a function of criteria acceptability;

7. analyse results to identify cause of problems;

8. postulate remedies by relating parameters to problem causes;

9. establish revised model to required resolution for each postulate;

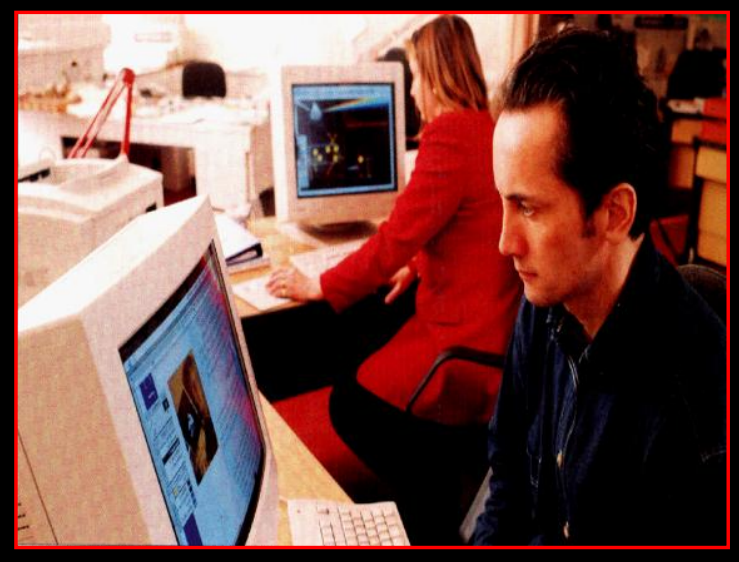

10. iterate from step 4 until overall performance is satisfactory;

11. repeat from step 3 to establish design replicability.

Standard PAMs required for all aspects of building life cycle performance: comfort, health \& productivity; operational \& embodied energy, emissions \& environmental impact, technology options appraisal, demand management, embedded generation, regulations compliance, hybrid systems control, economics, etc. - all utilising agreed simulation contexts and performance metrics and activated by the evolving data model. 


\section{$\underline{\text { Visualisations }}$}

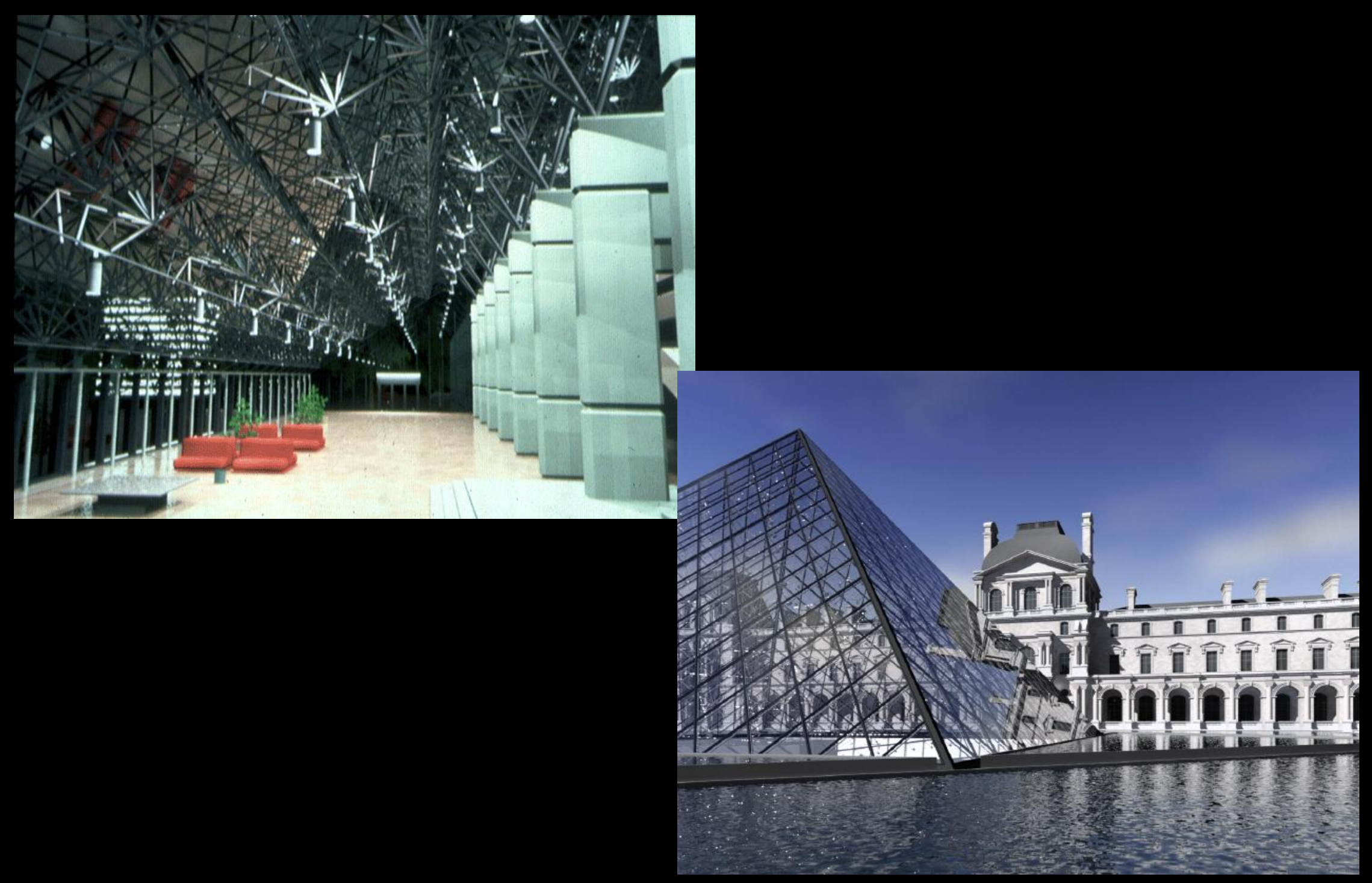




\section{Internal lighting}

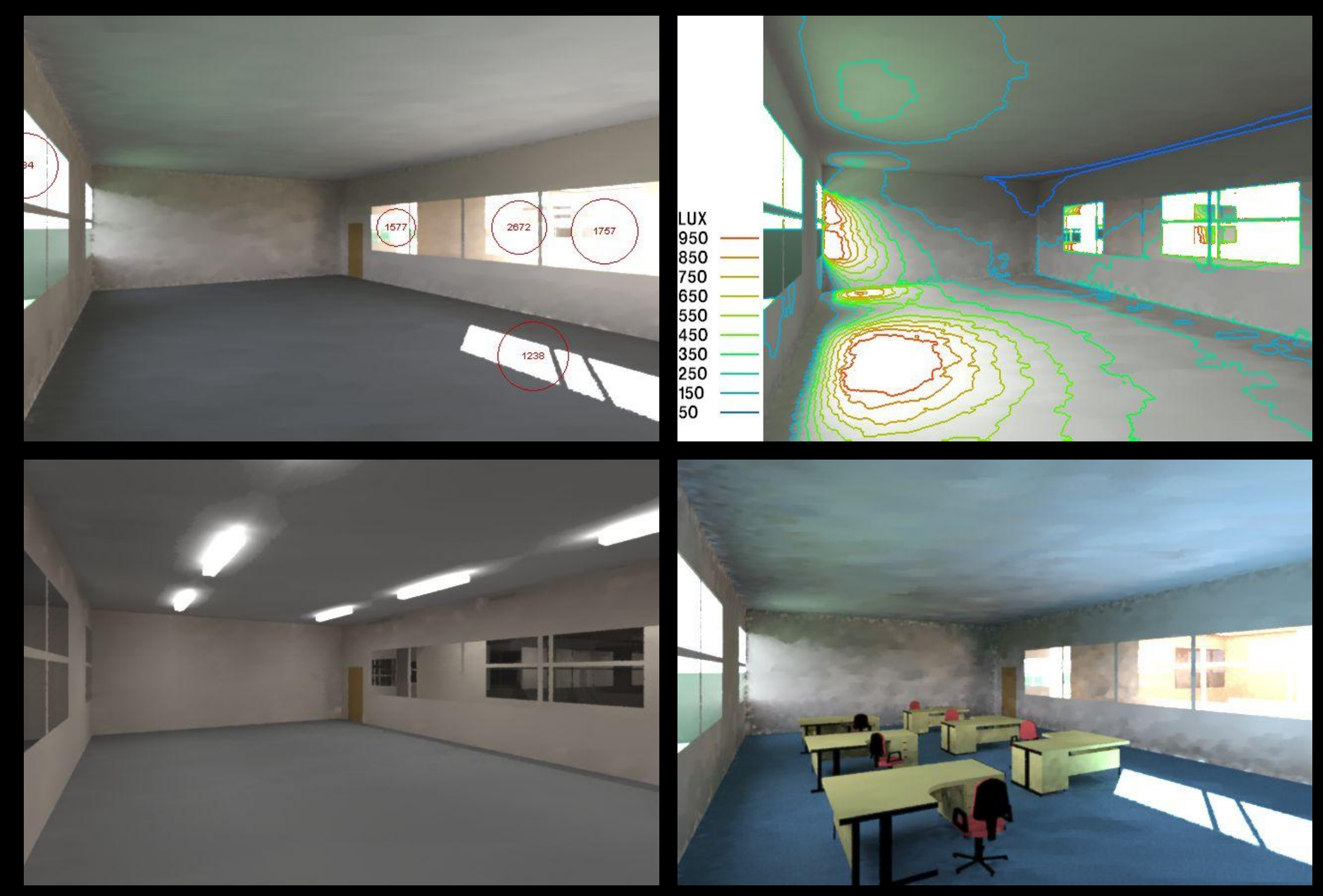




\section{Air flow and emissions}

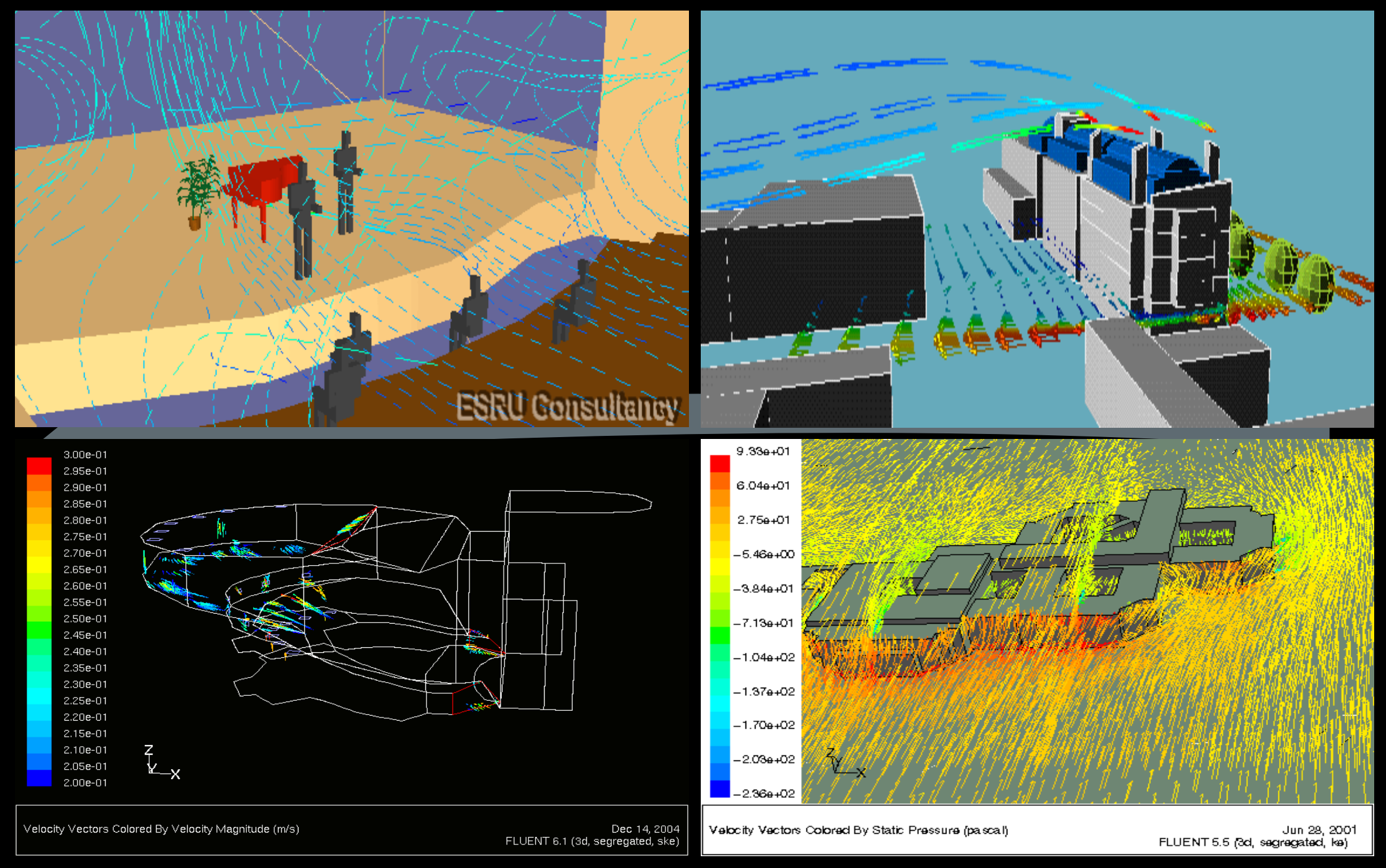




\section{$\underline{\mathrm{IAO} \& \text { comfort }}$}

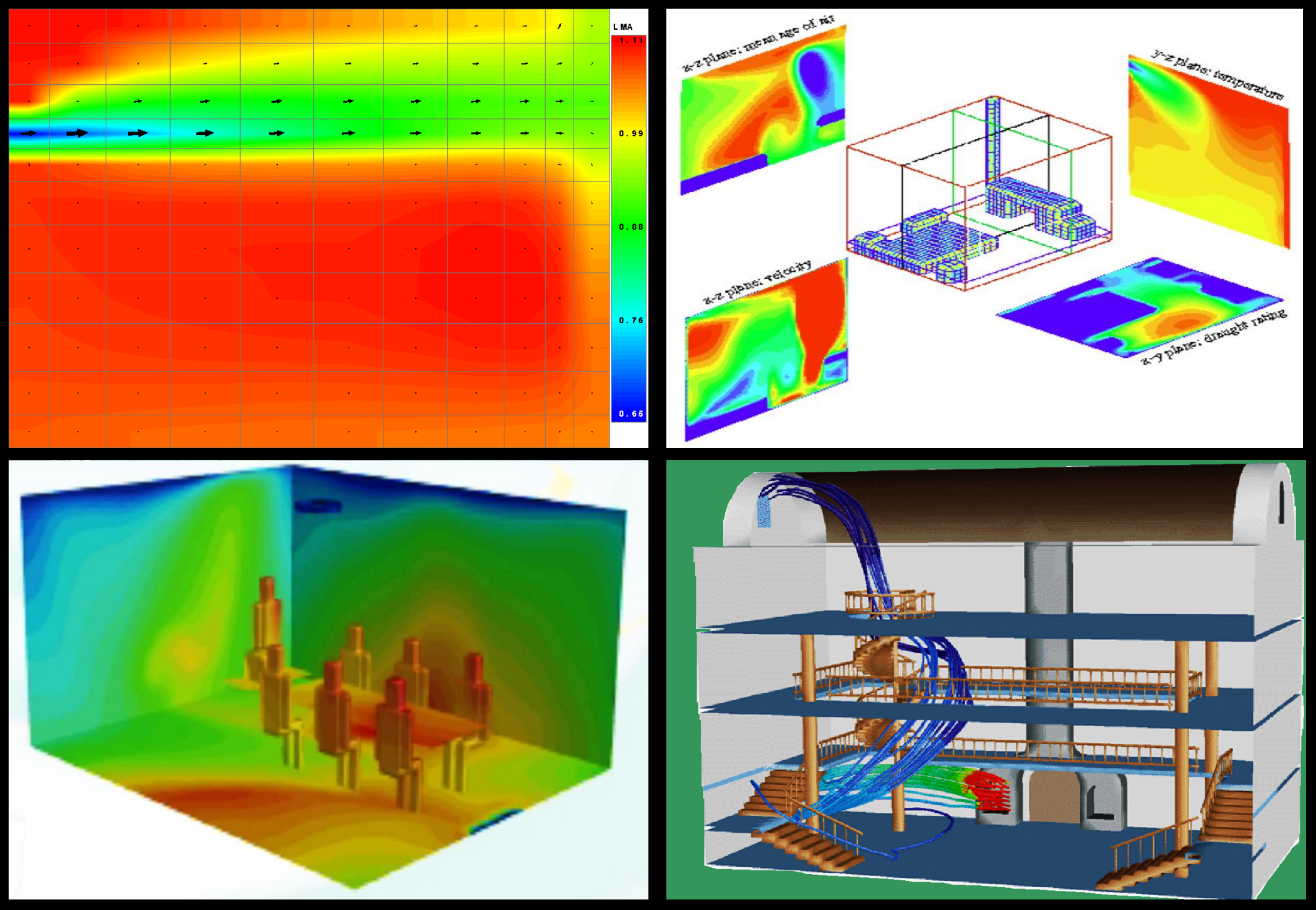




\section{Appropriate data presentation}
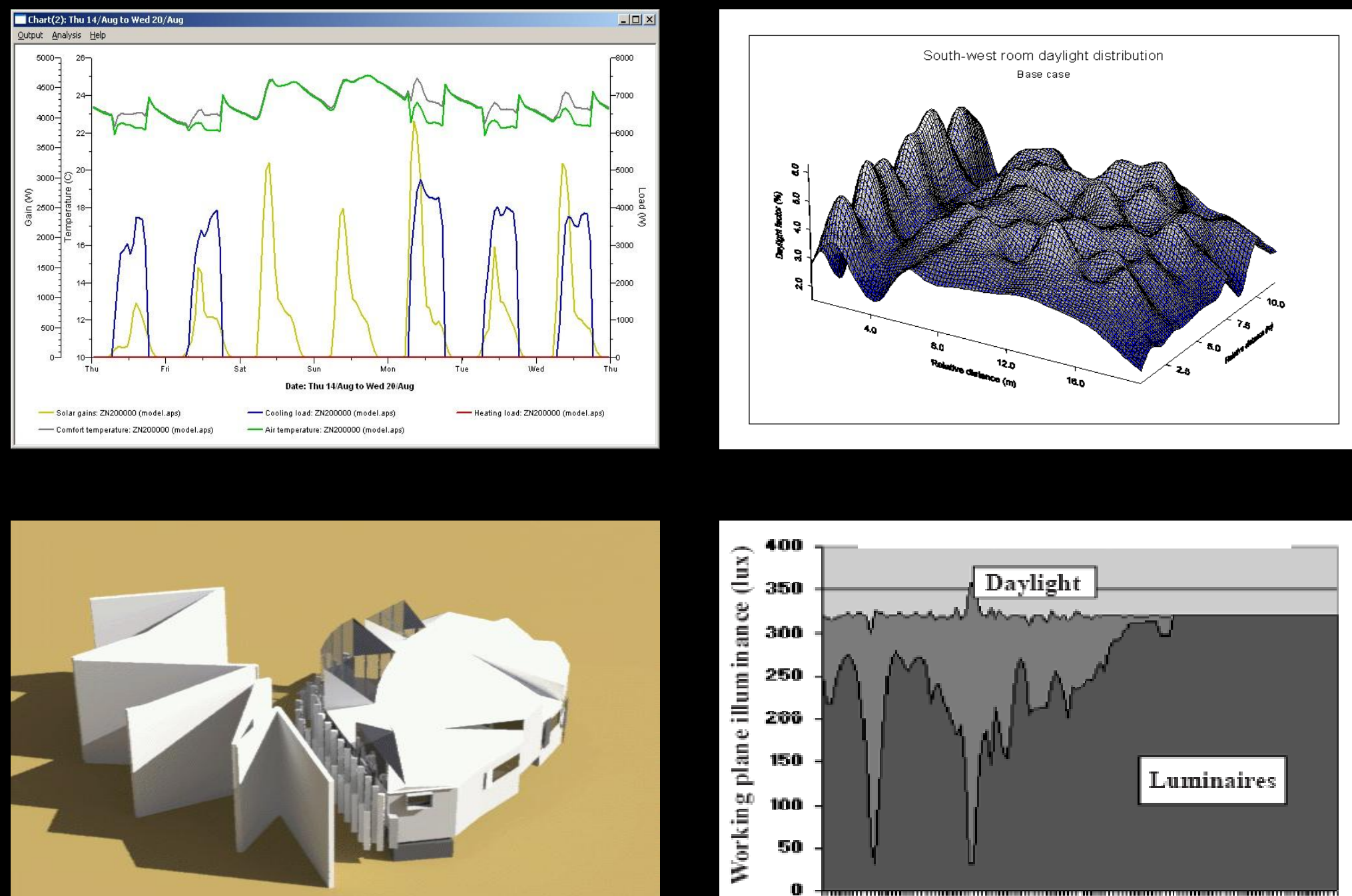

June 0609.00

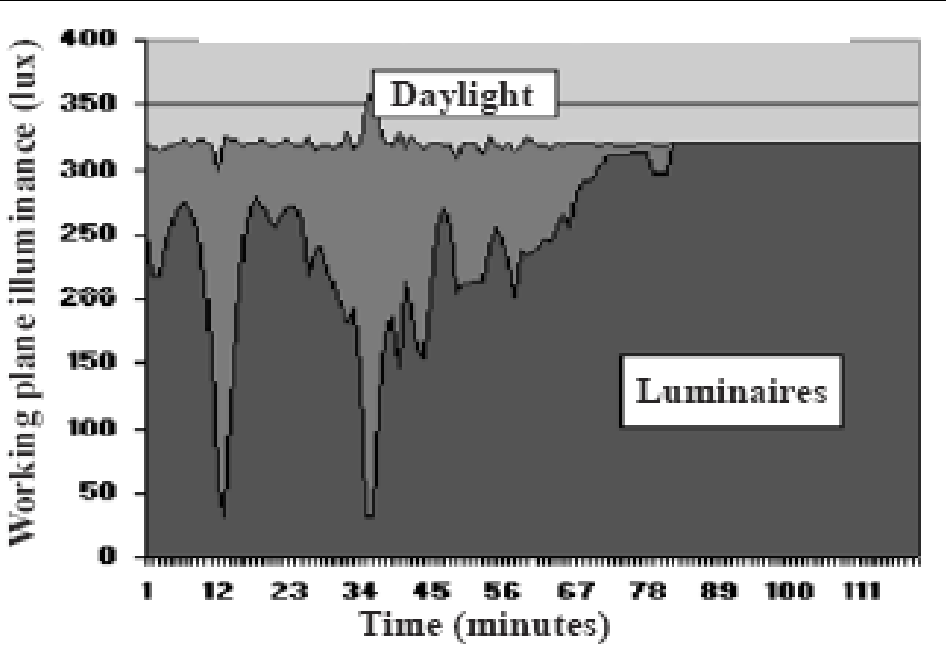




\section{Integrating renewables}
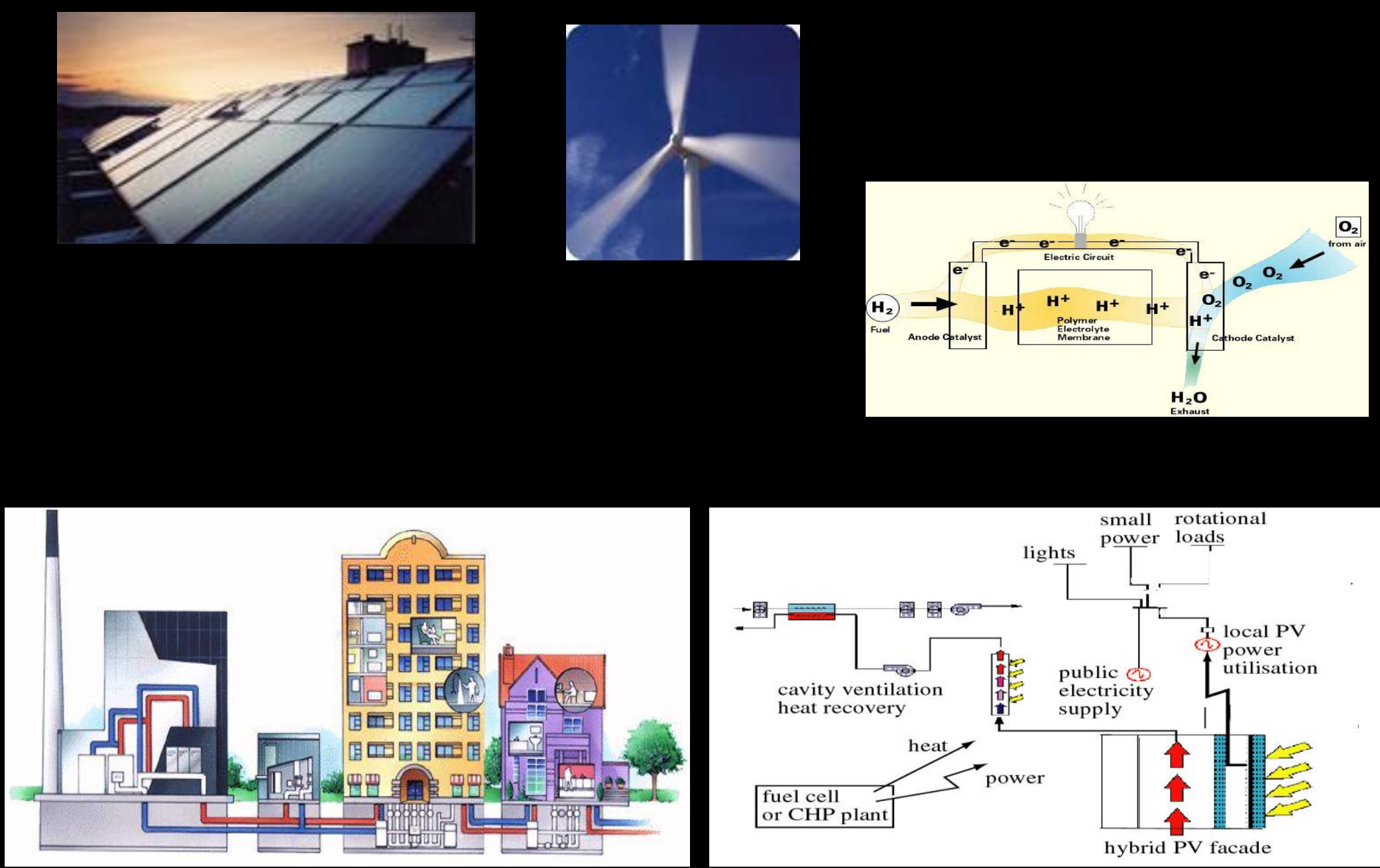


\section{Integrating renewables: the Lighthouse Building}
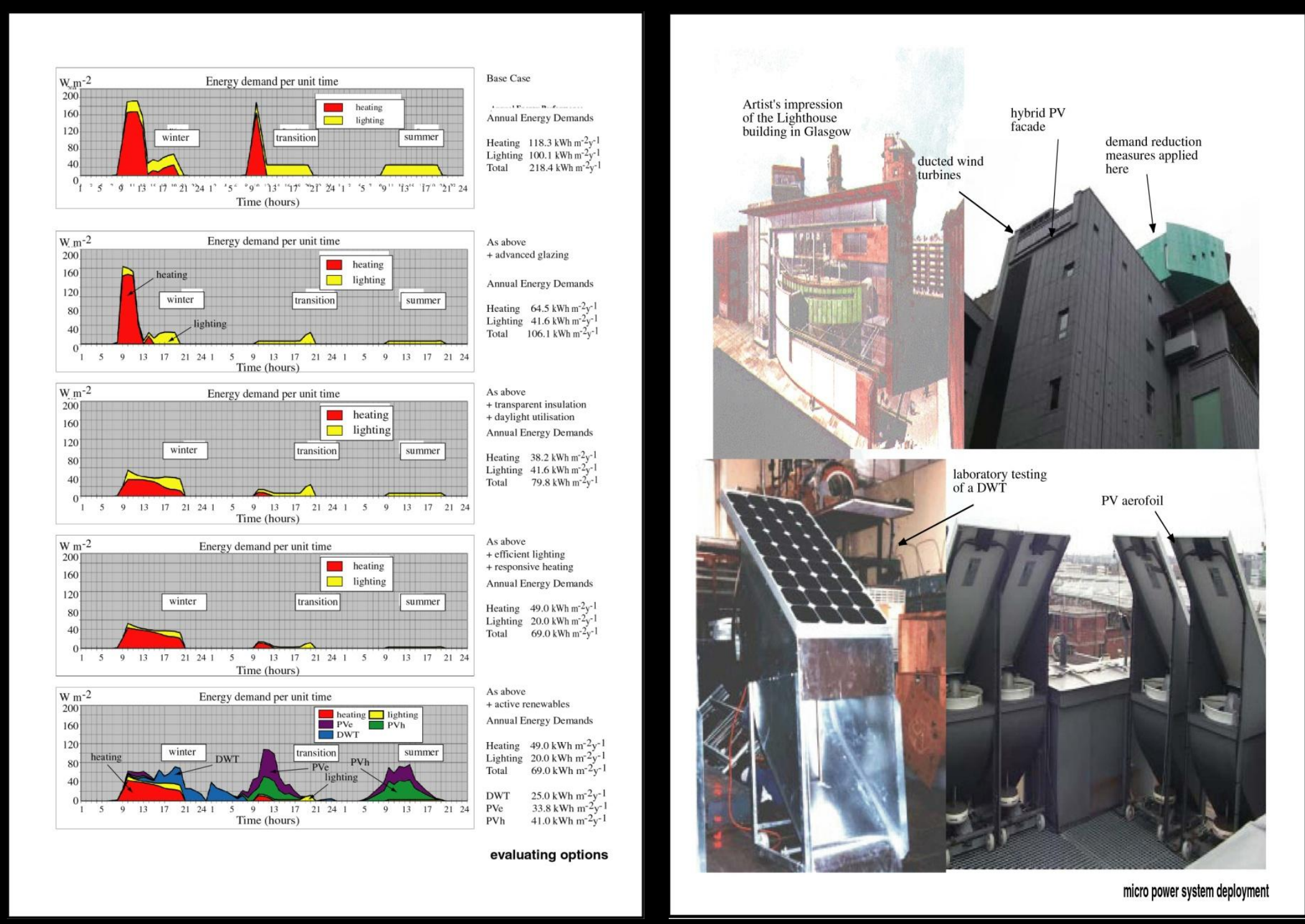


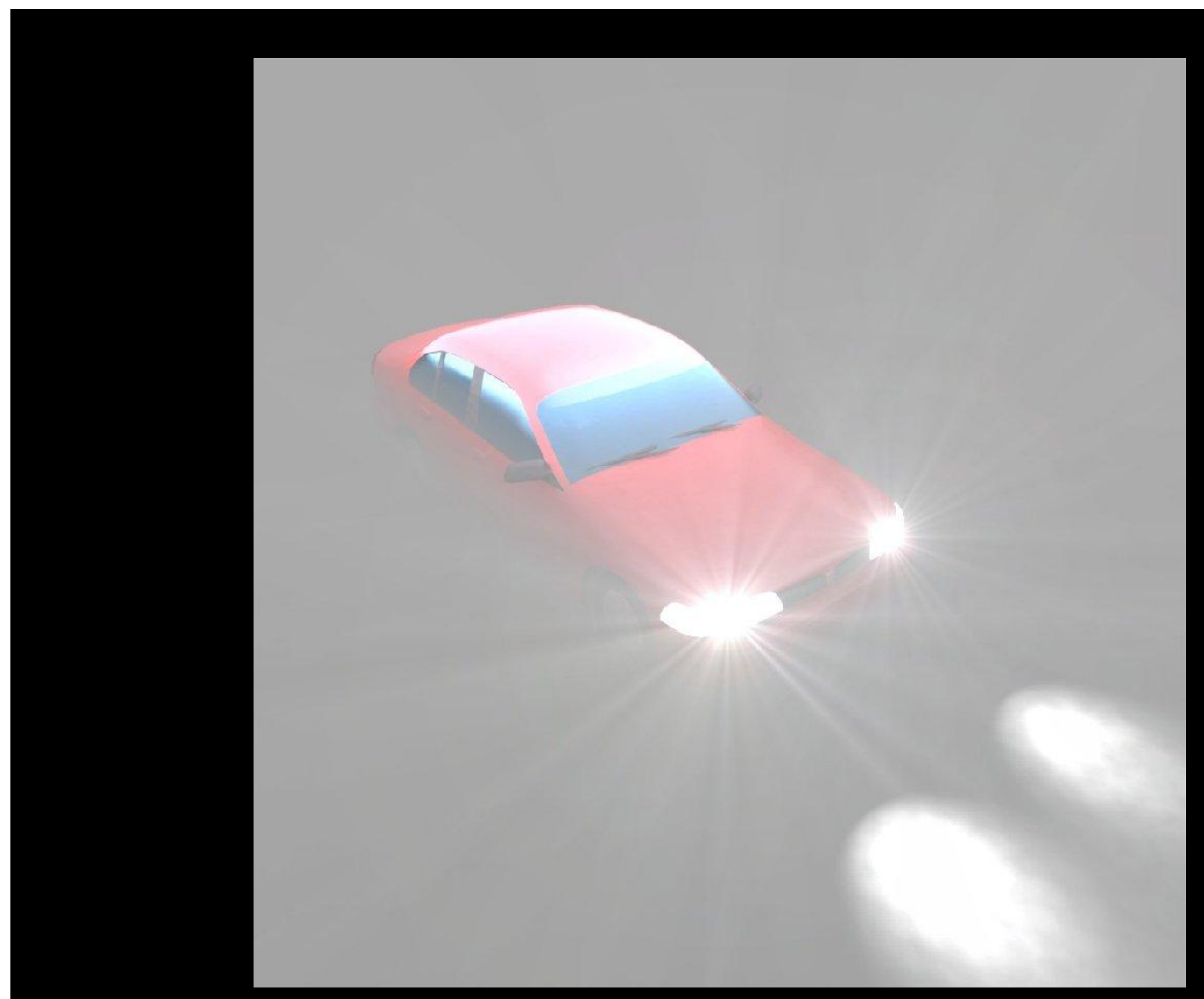




\section{Simulation-embedded CAD}

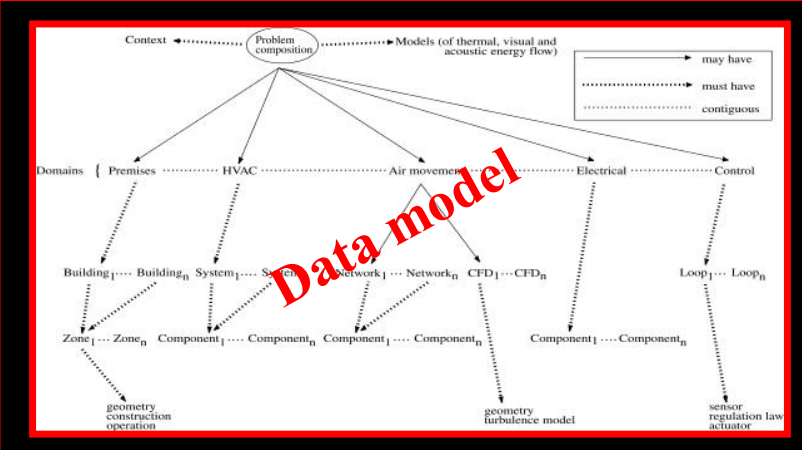

$\square$ IBPS defines the superset data model.

$\square$ CAD is the best agent for data model coordination.

Data model representation technologies exist.

$\square$ Need to extend the data model to non-traditional areas (use reality as the guide, not past engineering abstractions).

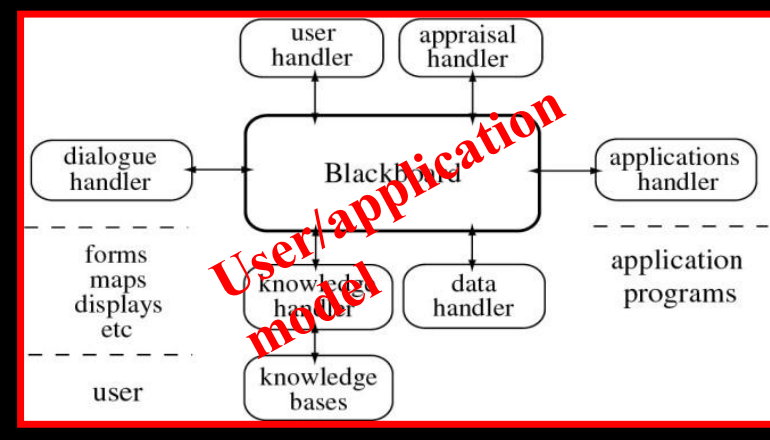

Need to separate out the different aspects of the user interface: user dialogue, user/domain/application knowledge, data management and application control.

- CAD is the best agent for coordinating such aspects.

$\square \mathrm{HCI}$ and user representation technologies exist and prototypes have been constructed and tested.

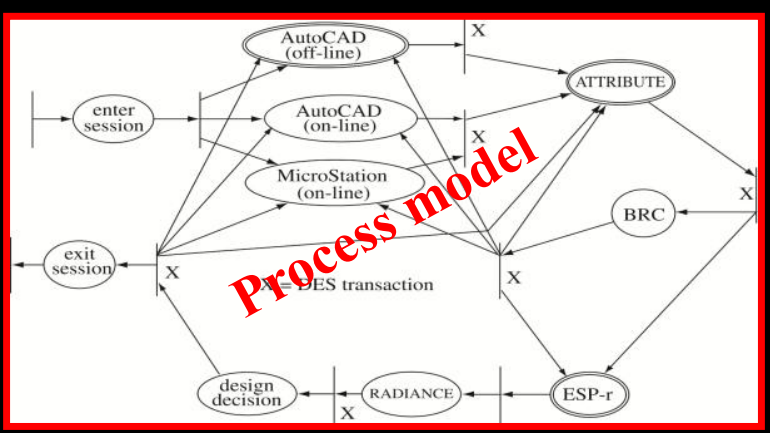

Need to formally define work flow models and performance assessment approaches.

CAD is the best agent for multi-variate performance assessment control.

Process representation technologies exist and prototypes have been constructed and tested. 


\section{Solver uncertainty}

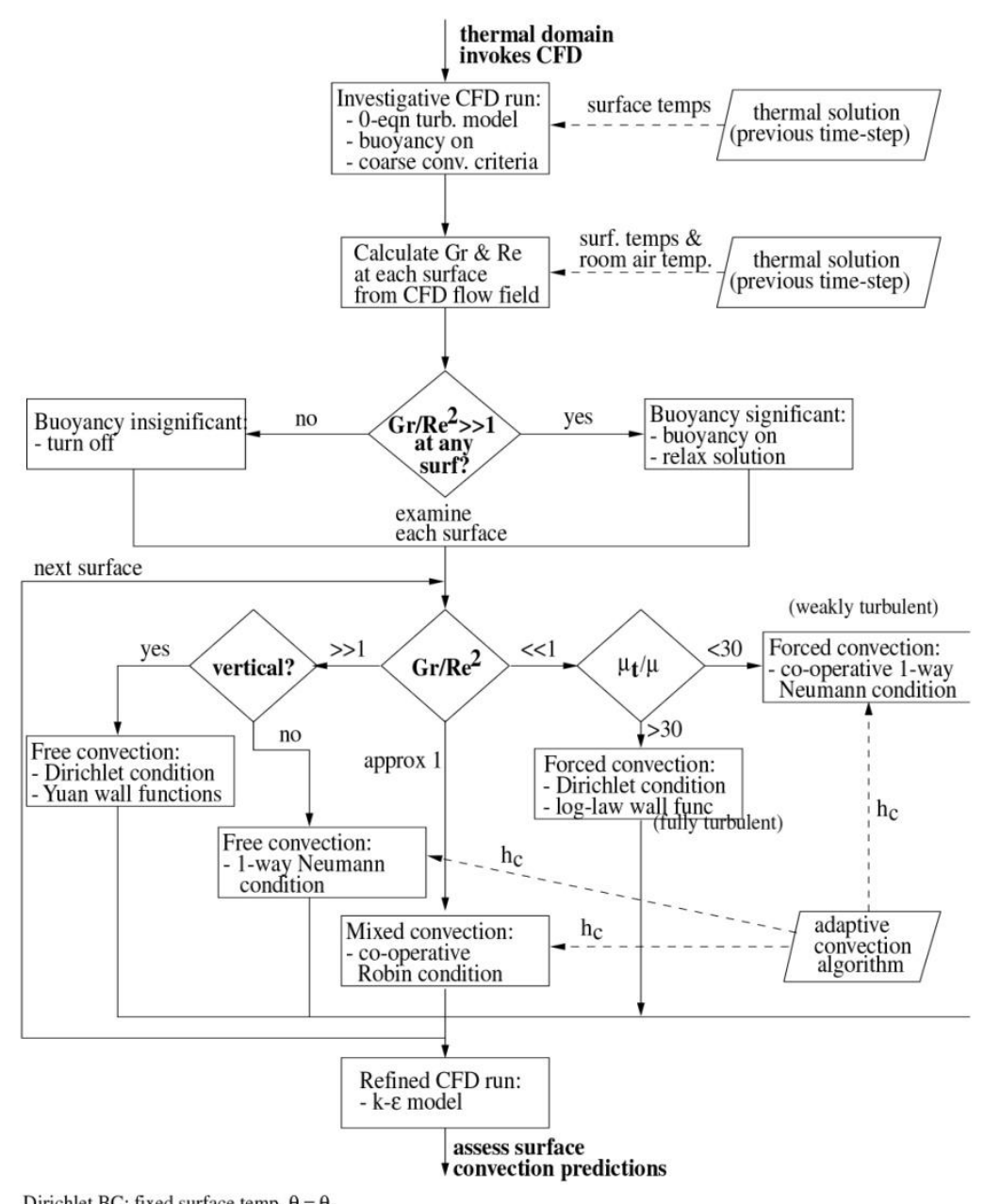

Neumann BC: fixed surface heat flux $k \frac{\delta \theta}{\delta \mathrm{n}}=q$

\begin{tabular}{|c|c|c|c|}
\hline $\begin{array}{c}\text { turbulence } \\
\text { model }\end{array}$ & $\begin{array}{c}\text { hand-shaking } \\
\text { mechanism }\end{array}$ & $\begin{array}{c}\text { CFD thermal } \\
\text { boundary condition }\end{array}$ & applicability \\
\hline \multirow{6}{*}{$\begin{array}{l}k-\varepsilon \text { model and } \\
\text { log-law wall functions } \\
\text { (for momentum eqs) }\end{array}$} & \multirow{4}{*}{ one-way } & $\begin{array}{l}\text { +Dirichlet } \\
\text { +CFD calculates } q_{\text {conv }} \\
\text { with log-law wall function }\end{array}$ & $\begin{array}{l}\text { +predicting flow \&temp. field } \\
\text { + not suitable for buoyancy-driven ow } \\
\text { + not suitable for o ws strongly affected by } q_{\text {com }}\end{array}$ \\
\hline & & $\begin{array}{l}\text { +Neumann } \\
\text { +thermal domain } \rightarrow T_{\text {suf }} \\
\text { +thermal domain } \rightarrow T_{\text {rom }} \\
+ \text { ACA } \rightarrow h_{c}\end{array}$ & $\begin{array}{l}\text { +predicting flow and temp. field } \\
\text { +suitable for flows strongly affected by } q_{\text {conv }}\end{array}$ \\
\hline & & $\begin{array}{l}\text { +co-op Neumann } \\
\text { +thermal domain } \rightarrow T_{\text {surf }} \\
+ \text { CFD } \rightarrow T_{\text {roum-air }}(\text { avg }) \\
+\mathrm{ACA} \rightarrow h_{c}\end{array}$ & $\begin{array}{l}\text { +predicting flow and temp.field } \\
\text { +suitable for flows strongly affected by } q_{\text {conv }} \\
\text { +useful when room straffied }\end{array}$ \\
\hline & & $\begin{array}{l}\text { +co-op Robin } \\
\text { +thermal domain } \rightarrow T_{\text {surf }} \\
+ \text { CFD } \rightarrow T_{p} \text { (local) } \\
+ \text { ACA } \rightarrow h_{c}\end{array}$ & $\begin{array}{l}\text { +prediction flow and temp.field } \\
\text { +suitable for flows strongly affected by } q_{\text {conv }} \\
\text { +useful when room stratified }\end{array}$ \\
\hline & \multirow{2}{*}{$\begin{array}{l}\text { conditional } \\
\text { two-way }\end{array}$} & $\begin{array}{l}\text { +Dirichlet } \\
\text { +CFD calculates } q_{\text {conv }} \\
\quad \text { with log-law wall functions }\end{array}$ & $\begin{array}{l}\text { +predicting flow and temp. field } \\
\text { +enhancing surface conv. calcs } \\
\text { +not suitable for buoynacy-driven flow } \\
\text { +not suitable for flows strongly affected by } q_{\text {com }} \text {, } \\
\text { +next-to-wall points must be properly placed }\end{array}$ \\
\hline & & $\begin{array}{l}\text { +co-op Robin } \\
\text { +thermal domain } \rightarrow T_{\text {suff }} \\
+ \text { CFD } \rightarrow T_{p} \text { (local) } \\
+A C A \rightarrow h_{c}\end{array}$ & $\begin{array}{l}\text { +predicting flow and temp. field } \\
\text { +enhancing surface conv. calcs } \\
\text { +suitable for o ws strongly affected by } q_{c o n v} \\
\text { +useful when room stratified }\end{array}$ \\
\hline \multirow{2}{*}{$\begin{array}{l}k-\varepsilon \text { model and } \\
\text { Yuan wall functions }\end{array}$} & one-way & $\begin{array}{l}\text { +Dirichlet } \\
\text { +CFD calculated } q_{\text {conv }} \\
\quad \text { with Yuan wall function }\end{array}$ & $\begin{array}{l}\text { +predicting flow and temp. field } \\
\text { +only suitable for buoyancy-driven flow } \\
\text { +only suitable for vertical surfaces }\end{array}$ \\
\hline & $\begin{array}{l}\text { conditional } \\
\text { two-way }\end{array}$ & $\begin{array}{l}\text { +Dirichlet } \\
\text { +CFD calculated } q_{\text {conr }} \\
\text { with Yuan wall function }\end{array}$ & $\begin{array}{l}\text { +predicting flow and temp. field } \\
\text { +enhancing surface conv. calcs } \\
\text { +only suitable for buoyancy-driven flow } \\
\text { +only suitable for vertical surfaces }\end{array}$ \\
\hline \multirow{2}{*}{$\begin{array}{l}\text { Chen \& Xu zero } \\
\text { equation model }\end{array}$} & one-way & $\begin{array}{l}\text { +Dirichlet } \\
\text { +CFD calculates } q_{\text {conv }}\end{array}$ & $\begin{array}{l}\text { +predicting flow and temp. field } \\
\text { +suitable for quick indication of flow } \\
\text { +less suitable for buoyancy-driven flow } \\
\text { +less suitable for flows strongly affected by } q_{\text {con }}\end{array}$ \\
\hline & $\begin{array}{l}\text { conditional } \\
\text { two-way }\end{array}$ & $\begin{array}{l}\text { +Dirichlet } \\
\text { +CFD calculates } q_{\text {conv }}\end{array}$ & $\begin{array}{l}\text { +predicting flow and temp. field } \\
\text { +enhancing surface conv. calcs } \\
\text { +less suitable for buoyancy-driven flow } \\
\text { +less suitable for flows strongly affected by } q_{\text {con }} \\
\text { +next-to wall points must be properly placed }\end{array}$ \\
\hline
\end{tabular}

turbulence model applicability 


\section{Modelling methods uncertainty}
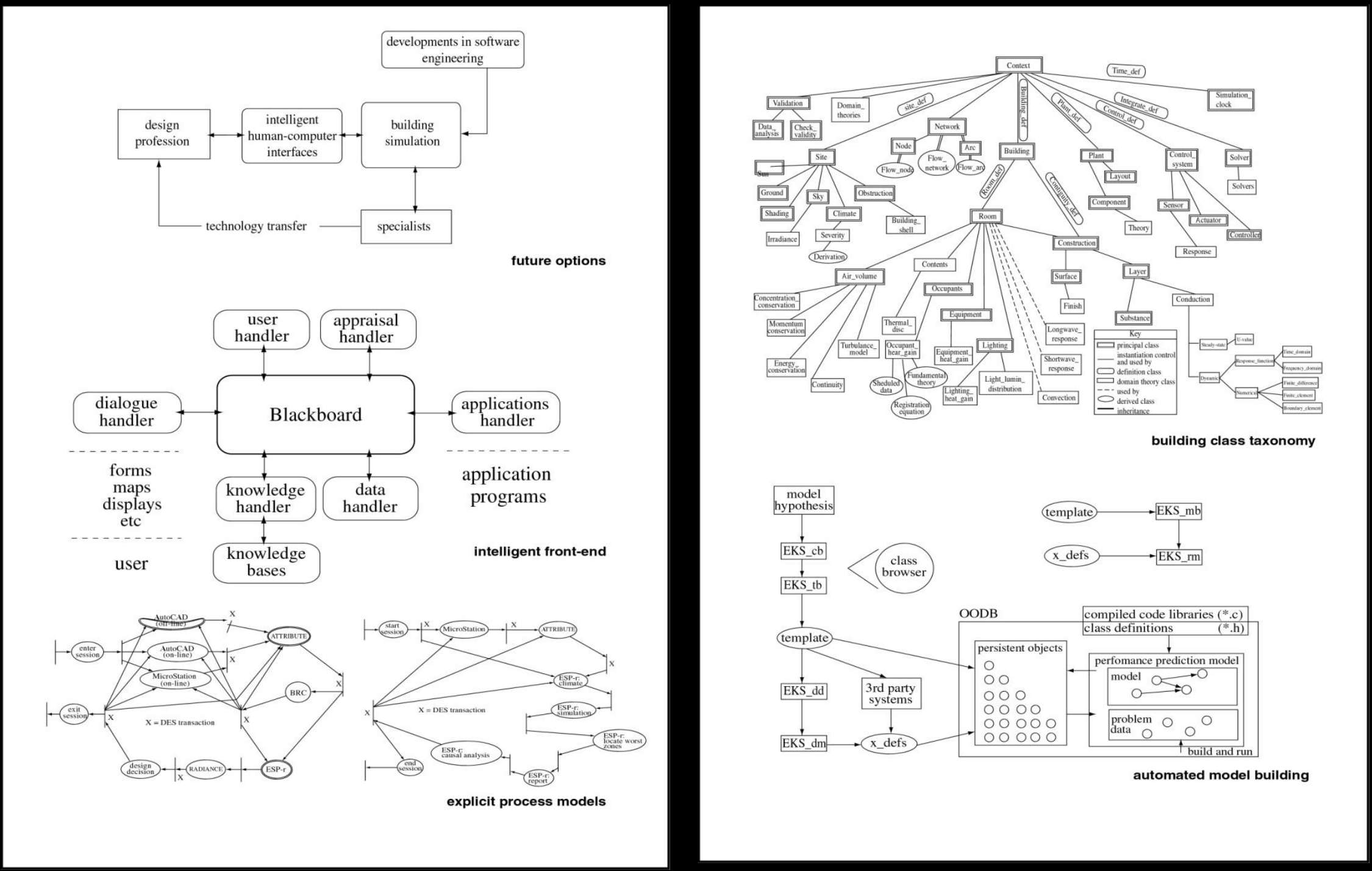
"The real need is to leave future generations with knowledge and capital, such that they can obtain a quality of life at least as good as ours, all in all."

Nobel Laureate, Robert Shaw
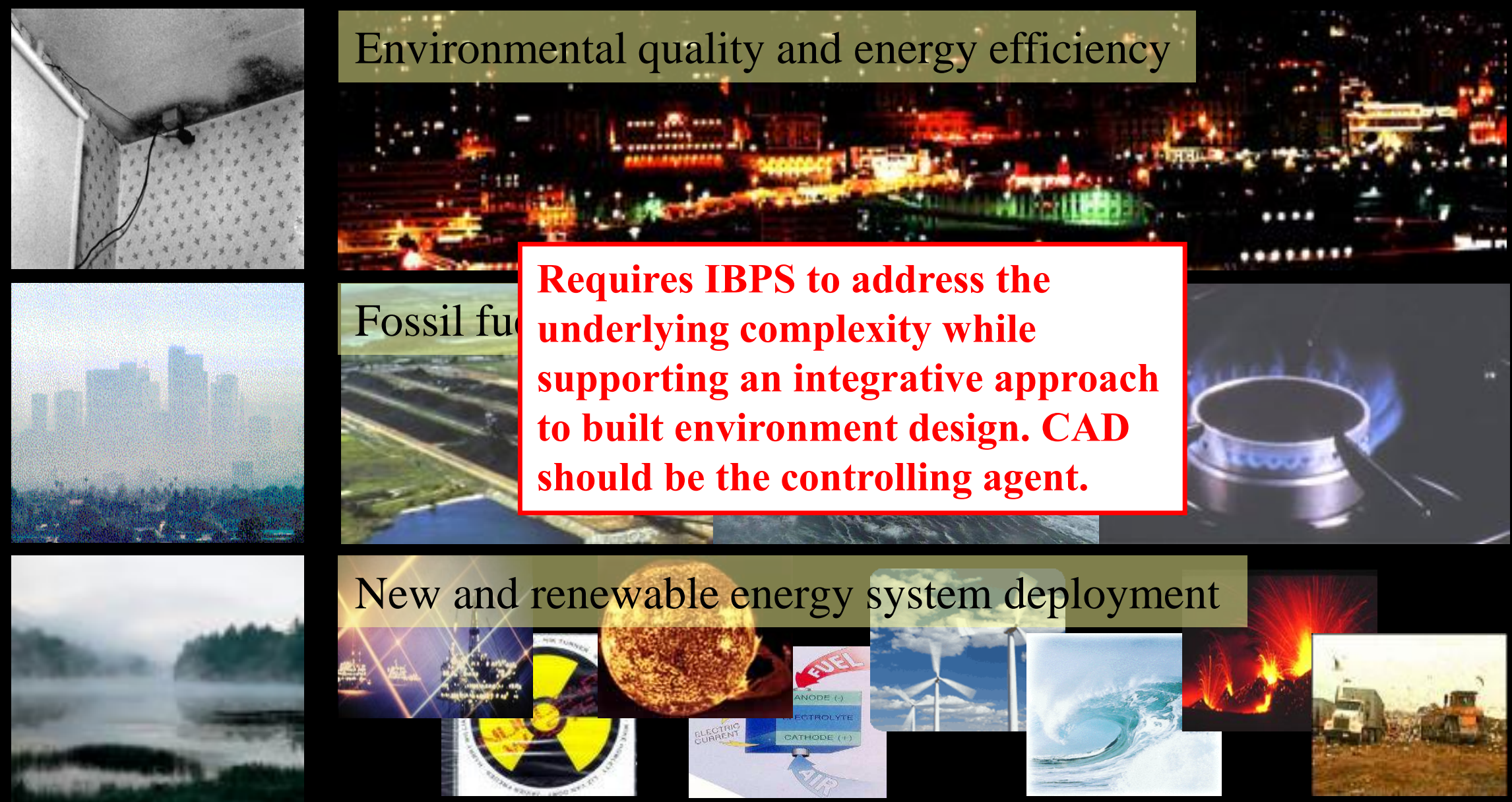

New and renewable energy system deployment

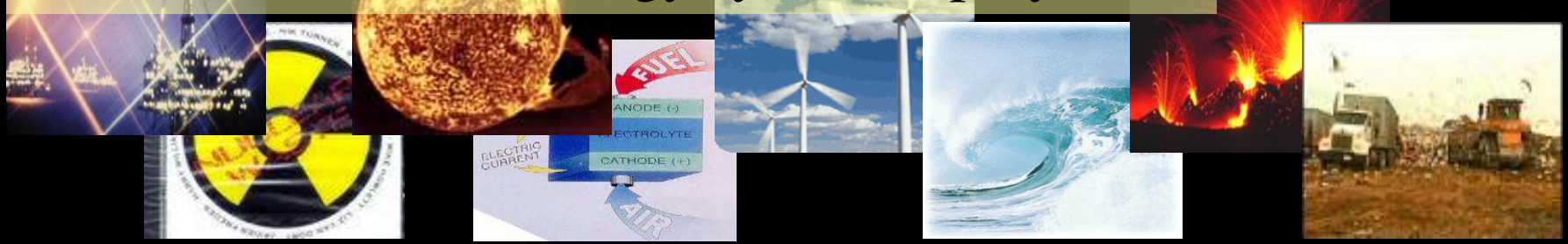




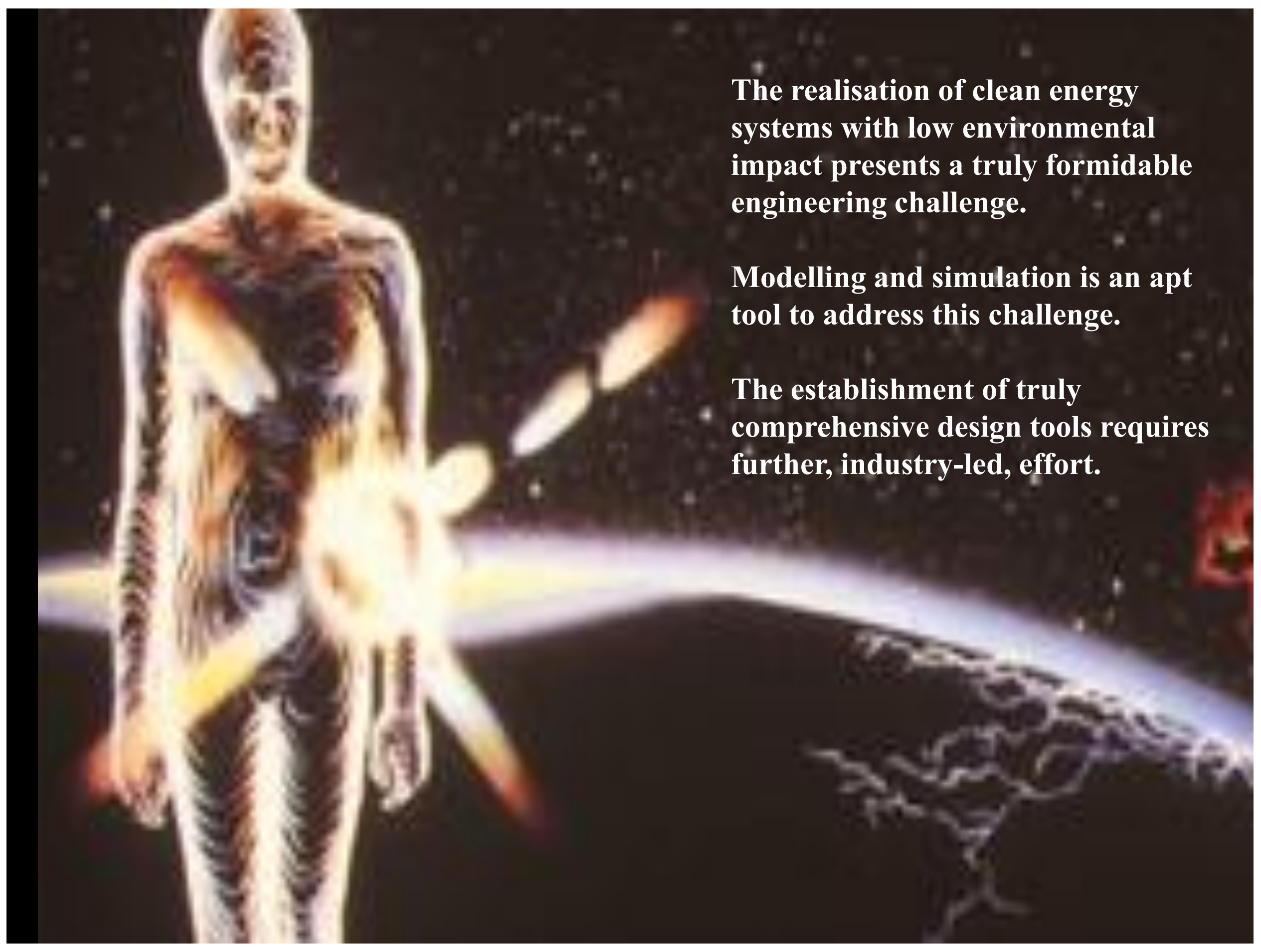

